\title{
STEPPING OFF THE WAGE ESCALATOR: THE EFFECTS OF WAGE GROWTH ON EQUILIBRIUM EMPLOYMENT
}

\author{
Michael W. L. Elsby \\ Matthew D. Shapiro \\ Working Paper 15117 \\ http://www.nber.org/papers/w15117
}
NATIONAL BUREAU OF ECONOMIC RESEARCH
1050 Massachusetts Avenue
Cambridge, MA 02138
June 2009

We would like to thank John Bound, Charlie Brown, Damon Clark, Robert Hall, Chris House, Miles Kimball, David Romer, and Gary Solon for helpful comments, Chinhui Juhn and Lance Lochner for sharing their data at the early stages of this project, and David Ratner for excellent research assistance. We also thank participants in seminars at the Einaudi Institute for Economics and Finance, Stanford, Berkeley, the New York Fed, the Hebrew University, Tel Aviv, Michigan State, Edinburgh, Ohio State, Toronto, Michigan, Warwick, and Florida. The views expressed herein are those of the author(s) and do not necessarily reflect the views of the National Bureau of Economic Research.

NBER working papers are circulated for discussion and comment purposes. They have not been peerreviewed or been subject to the review by the NBER Board of Directors that accompanies official NBER publications.

(C) 2009 by Michael W. L. Elsby and Matthew D. Shapiro. All rights reserved. Short sections of text, not to exceed two paragraphs, may be quoted without explicit permission provided that full credit, including $\odot$ notice, is given to the source. 
Stepping Off the Wage Escalator: The Effects of Wage Growth on Equilibrium Employment Michael W. L. Elsby and Matthew D. Shapiro

NBER Working Paper No. 15117

June 2009

JEL No. E24,J2,J3

\begin{abstract}
$\underline{\text { ABSTRACT }}$
This paper emphasizes the role of wage growth in shaping work incentives. It provides an analytical framework for labor supply in the presence of a return to labor market experience and aggregate productivity growth. A key finding of the theory is that there is an interaction between these two forms of wage growth that explains why aggregate productivity growth can affect employment rates in steady state. The model thus speaks to an enduring puzzle in macroeconomics by uncovering a channel from the declines in trend aggregate wage growth that accompanied the productivity slowdown of the 1970s to persistent declines in employment.

The paper also shows that the return to experience for high school dropouts has fallen substantially since the 1970s, which further contributes to the secular decline in employment rates. Taken together, the mechanisms identified in the paper can account for all of the increase in nonemployment among white male high school dropouts from 1968 to 2006. For all white males, it accounts for approximately one half of the increase in the aggregate nonemployment rate over the same period.
\end{abstract}

Michael W. L. Elsby

University of Michigan

Department of Economics

238 Lorch Hall

611 Tappan Street

Ann Arbor, MI 48109-1220

and NBER

elsby@umich.edu

Matthew D. Shapiro

Department of Economics

University of Michigan

611 Tappan St

Ann Arbor, MI 48109-1220

and NBER

shapiro@umich.edu 


\section{Introduction}

Rates of joblessness in the U.S. have varied substantially over time. As a secular phenomenon, the aggregate rate of nonemployment among prime age white males has doubled since the late 1960s (see Figure 1A). These trends are driven by dramatic declines in labor market attachment among the low-skilled. For high school dropouts, trend nonemployment surged from 7 percent in the late 1960s up to 25 percent in recent years (Figure 1B).

Explaining the variation in U.S. joblessness over time has been a central question for labor and macroeconomics and for public policy for several decades. Among the first to document the dramatic secular rise in rates of nonemployment, and its concentration among the low-skilled were two influential papers by Juhn, Murphy and Topel (1991, 2002). They suggest that an important driving force to these trends was the decline in the demand for low-skilled workers that occurred in the 1970s and 1980s.

This paper identifies a novel and complementary explanation for these trends. We emphasize the role of wage growth in shaping work incentives. The results of our analysis reveal that variation in wage growth can help explain increased rates of joblessness among low-skilled males in the U.S. through two channels: First, through reductions in the returns to labor market experience among high school dropouts over time; and second, through reductions in economy-wide wage growth that accompanied the productivity slowdown of the 1970s. Together, we show that these trends in wage growth can account for all of the secular rise in low-skilled joblessness between the late 1960s and recent years, and for one half of the increase in aggregate joblessness among white males.

We arrive at these conclusions by formulating a model of equilibrium employment that incorporates wage growth through returns to labor market experience as well as aggregate productivity growth. The model reveals that the joint processes of the accumulation of labor market experience and the decision to supply labor are naturally intertwined: In order to accumulate experience, an individual must work. The interaction between these 
two processes in the model generates a strong theoretical rationale for a connection between rates of wage growth and the level of equilibrium employment. We show that changes in the experience-earnings profile that workers face affect the decision of a marginal worker to seek lifetime employment. Intuitively, if the "wage escalator" flattens due to a decline in the return to experience, the payoff to being engaged in the workforce over a lifetime falls, and a marginal worker will find employment a less attractive prospect.

The connection between wage growth and work incentives in our model speaks to an enduring puzzle in the macroeconomics of labor markets. In particular, our model uncovers a channel from reductions in aggregate wage growth to long run reductions in the level of aggregate employment. Economists have long been tempted to relate the decline in economy-wide wage growth associated with the productivity slowdown of the 1970 s to the persistent deterioration in equilibrium employment beginning in the early to mid-1970s. A prominent early example is Bruno and Sachs (1985). More recently, Staiger, Stock, and Watson (2001, Figure 1.9) have emphasized the striking negative secular correlation between productivity growth and unemployment. In particular, Stock has posted this "intriguing graph" on his webpage for the last number of years as an implicit challenge to the economics profession to explain it. ${ }^{1}$

Superficially, the case for a link between productivity growth and employment rates appears simple: Should it be surprising that employment declines when the returns to work have fallen? The theoretical link between productivity growth and equilibrium employment, however, has proved elusive. Blanchard (2007) surveys modern models of the aggregate labor market and concludes that they "deliver, to a first order, long run neutrality of unemployment to productivity growth." While existing theories may have different implications for the short and medium run effects of productivity growth, he concludes that our understanding of the link between productivity and employment is weak: "The truth is we do not know. And this

\footnotetext{
${ }^{1}$ See http://ksghome.harvard.edu/ $\sim$ JStock/. We focus on nonemployment rather than unemployment because of the significant secular increase in nonparticipation observed among men since the $1970 \mathrm{~s}$.
} 
is a serious hole in knowledge" (Blanchard, 2007, p.416).

As our theory makes clear, traditional models of employment determination have the implication that permanent changes in productivity growth leave equilibrium employment rates unchanged: In any model with a steady state, changes in productivity growth should equally affect the returns to work and the returns to not working, as any violation of this relation will cause an economy to converge either to full employment or zero employment in the long run.

Our model bridges this gap in the literature. It shows that aggregate wage growth interacts with the returns to experience in determining equilibrium employment. Over a working life, aggregate wage growth acts like compound interest on a positive return to experience. In this way, a positive return to experience levers the effect of productivity growth on the lifetime payoff from working. Consequently, this provides a mechanism through which changes in aggregate wage growth can affect equilibrium employment.

A final contribution of our analysis is to highlight an important life-cycle dimension to these effects. Using our model we show that the labor supply of older workers is predicted to be less responsive to shocks relative to younger workers. This outcome arises from a natural interaction between finite working lifetimes and the presence of a return to experience. Older workers become less marginal to shocks both because they have accumulated substantial work experience, and because they have a shorter remaining working life over which shocks to wage growth can affect their earning potential. Consequently, our model predicts that the rise in joblessness among the low-skilled initially should be concentrated among younger workers, who are more marginal to the employment decision. Consistent with this, rates of nonemployment among high school dropouts below the age of 40 rose faster than for their older counterparts in the data.

The plan of the paper is as follows. In Section II, we present a very simple model of labor supply in the presence of a return to experience and aggregate wage growth in 
order to provide the basic qualitative intuition for the effects we emphasize. In Section III, we then present empirical results that confirm the substantial changes in the return to experience and aggregate wage growth among low-skilled, marginal workers. Using data from the decennial Censuses and the American Community Survey, we provide evidence on the experience-earnings profile for different skill groups over time in the U.S. This exercise reveals a little-known empirical trend: The experience-earnings profile among high school dropouts flattened between 1970 and 2000. Moreover, the magnitude of these effects is substantial. The capitalized value of earnings over the first thirty years of working life declined by nearly 50 percent since 1970 for high school dropouts. In Section IV, we extend the simple model of Section II to account for finite worker lifetimes, as well as nonlinear experience-earnings profiles. Using this generalized model, we then draw out the quantitative implications of the observed changes in wage growth documented in Section III. In Section V we discuss how this paper relates to the literature. In Section VI, we offer conclusions.

\section{Basic Model}

Before we delve into a more elaborate model of the decision to supply labor in the presence of returns to experience, in this section we first present a simple model that delivers our basic insights on the interaction of aggregate wage growth and the return to labor market experience and its role in the determination of incentives to work.

Consider a simple environment in which there are two employment states, employment and nonemployment, and workers choose whether they want to supply their labor or not. The critical addition that we explore relative to previous literature is to allow for two forms of wage growth - growth in starting wages, and returns to labor market experience - as well as growth in the flow payoff from nonemployment. Note that the phenomenon we are aiming to model is the life-long choice that a worker makes to be committed to the labor market 
and therefore accrue the returns to experience. Consequently, we abstract from frictional episodes of unemployment between jobs. Adding frictional unemployment would complicate the model, but not alter its central messages.

Consider an infinitely lived worker $i$ who must make a once-and-for-all decision at the start of his (non-) working life between working forever and not working forever. If he works, he accumulates a year of labor market experience $x$ for every year he works, and faces a wage profile $w_{i}(x, t)$. Assume that there is a return to experience $g_{x}$, and aggregate wage growth $g_{w}$, such that

$$
\ln w_{i}(x, t)=\ln w_{i}(0,0)+g_{x} x+g_{w} t
$$

It is straightforward to derive this as the labor demand equation implied by a constant returns to scale production technology with fully flexible inputs, in which a worker with experience $x$ accounts for $e^{g_{x} x}$ efficiency units of labor, and labor augmenting technical progress occurs at rate $g_{w}$ over time (see the Appendix for a derivation). If the individual decides not to work, he does not accumulate experience, and he receives a payoff from nonemployment equal to $b_{i}(t)$. Assume that the latter grows over time at rate $g_{b}{ }^{2}$

In this simple environment, all the worker need do is choose the option that delivers the highest present value of lifetime earnings. In particular, if the discount rate is equal to $r$, it is straightforward to show that a newborn potential worker at time $t$ will decide to work if his offered wage, $w_{i}(0, t)$ exceeds a reservation wage equal to

$$
w_{i}(0, t) \geq w_{R i}(t)=\alpha b_{i}(t), \text { where } \alpha \equiv \frac{r-g_{w}-g_{x}}{r-g_{b}} .
$$

\footnotetext{
${ }^{2}$ In this context, the flow payoff from nonemployment $b$ must include much more that unemployment compensation, which has short duration in the U.S. Empirically, much of the secular rise in nonemployment in the U.S. is accounted for by increases in very persistent (full-year) nonemployment spells (Juhn, Murphy and Topel, 1991, 2002). In addition, the model we present is one of the life-long decision to work. It is surprising to us how little work has been done to document the sources of income that persistently nonemployed individuals face in the U.S. Possible interpretations of $b$ include the income of other household members, income from employment in turbulent jobs with limited human capital accumulation, the value of home production and leisure, as well as public health insurance, disability insurance and social security.
} 
This simple formulation for the reservation wage relies on an infinite horizon specification and an assumption of geometric growth in this simple model. In Section IV below, we present a more general model that preserves the intuition of this formulation for the reservation wage while taking into account a more realistic specification of the trajectory of wages.

\section{A Wage Growth and Steady-State Employment}

A number of insights follow from the simple observation in equation (2). First note that, while the reservation wage grows over time at the same rate as the payoff from nonemployment, $g_{b}$, the wage of a newborn worker, $w(0, t)$, grows at the rate of aggregate wage growth, $g_{w}$. To see the significance of this, imagine an economy populated by workers facing different wage profiles, $w_{i}(x, t)=\omega_{i} w(x, t)$, and different payoffs from nonemployment, $b_{i}(t)=\beta_{i} b(t)$, but who otherwise face the same labor supply problem. The variables $\omega_{i}$ and $\beta_{i}$ thus represent heterogeneity in skill and the payoff from nonemployment respectively. It follows that the steady-state employment rate in this economy will be given by

$$
L^{*}=\operatorname{Pr}\left[w_{i}(0, t) \geq \alpha b_{i}(t)\right]=1-\Omega(\alpha \rho),
$$

where $\Omega(\cdot)$ is the c.d.f. of the ratio $\omega_{i} / \beta_{i}$, and $\rho \equiv b(t) / w(0, t)$ is the replacement rate for newborn workers.

For employment to be in steady state, the replacement rate $\rho$ must be stationary. The replacement rate will be stationary only if the growth rate of the payoff from nonemployment must equal to the rate of aggregate wage growth, $g_{b}=g_{w}$ in steady state. To see why, imagine for example that $g_{b}>g_{w}$. In this case, the employment rate will converge to zero over time as the payoff from nonemployment increasingly dominates the payoff from work. A symmetric logic holds for the case where $g_{b}<g_{w}$. Imposing the restriction required for a 
steady state to exist, $g_{b}=g_{w}$, implies that the reservation wage may be rewritten as

$$
w_{R i}(t)=\alpha b_{i}(t), \text { where } \alpha \equiv 1-\frac{g_{x}}{r-g_{w}} .
$$

Note that the constraint $g_{w}=g_{b}$ is not special to our formulation. Any model with a steady state will have to impose it.

Together, equations (3) and (4) characterize the determinants of incentives to work in this simple environment. We observe that changes in employment are driven by changes in either $\alpha$ or $\rho$. The effects of changes in the replacement rate $\rho$ are simple and wellunderstood: A higher replacement rate renders nonemployment more attractive and reduces steady state labor supply. The latter effect is a very conventional long run property of models of equilibrium employment (see Blanchard, 2000; Layard, Nickell and Jackman, 1991, among others). The determinants of the variable $\alpha$ are less common in the literature - the return to labor market experience, $g_{x}$, and the rate of aggregate wage growth, $g_{w}$. We now explore these effects in more detail.

Consider first the effects of the return to experience. Note from equation (4) that a positive return to experience, $g_{x}>0$, drives a worker's reservation wage below his flow payoff from nonemployment. The reason is simple: If workers anticipate positive returns to experience, they will forgo earnings in the short run in order to reap the returns to experience in the long run. This effect is neglected in macroeconomic models where wage growth is linked only to the level of productivity and not to labor market experience.

A corollary of this observation is that increases in the return to experience will reduce reservation wages even further below the flow payoff from nonemployment, and therefore will lead to increased employment rates. The reason is that increases in the return to experience raise the present discounted value of earnings from working relative to not working. Moreover, such changes in the return to experience are likely to have high-powered effects on work incentives. Intuitively, this is for the familiar reason that changes in the rate of growth of 
an income stream have large effects on the present discounted value of that stream, which is what matters for employment incentives in the model, due to compounding. Mechanically, this can be verified by noting that the denominator, $r-g_{w}$, in equation (4) is likely to be small for reasonable values of the interest rate, $r$, and aggregate wage growth, $g_{w}$.

Now consider the effects of a change in the rate of aggregate wage growth, $g_{w}$. Equation (4) suggests that, when the return to experience is positive, increases in the rate of aggregate wage growth will lead to a reduction in reservation wages, and thereby an increase in aggregate employment. The simple reason is that greater aggregate wage growth interacts with the return to experience by compounding the rate of wage growth relative to the growth of the payoff from nonemployment. Aggregate wage growth acts like compound interest on the return to experience. ${ }^{3}$ It is important to note that the latter effect of aggregate wage growth on incentives to supply labor is absent in traditional models of aggregate employment determination which abstract from returns to experience and implicitly set $g_{x}=0$. It is this feature of standard models of equilibrium employment that Blanchard (2007) emphasizes as a hole in our understanding of aggregate labor markets.

The perceptive reader will observe that the effect of aggregate wage growth in our model is driven by the specification that experience is multiplicative, not additive, in determining wages, i.e. that the Mincerian wage equation be specified in logarithms rather than in levels. The specification that experience and productivity are multiplicative is, however, much deeper than a functional form restriction. If the returns to experience were additive in wages, i.e., a fixed amount rather than fixed percentage, then the returns to experience would become vanishingly small over time if there is a positive trend to productivity. So an additive specification for experience is asymptotically equivalent to assuming no return to

\footnotetext{
${ }^{3}$ The mechanism for the effect of $g_{w}$ on employment incentives, though simple, can appear subtle. A natural question is whether this mechanism requires any more than the usual ingenuity that we ask of individuals when we apply our economic models to the real world. Our sense is that it does not. Individuals in the model do not care about the composition of wage growth between aggregate wage growth, and returns to experience; they only have to keep track of overall growth in wages. The mechanism can appear subtle to economists because we care about delineating the separate effects of $g_{w}$ and $g_{x}$.
} 
experience at all.

\section{B Where Shocks Hit Hardest: The Importance of Marginal Work- ers}

The simple model of this section adds two novel determinants of variation in the aggregate employment rate: the return to experience and the rate of aggregate wage growth. A more precise expression for the effects of changes in $g_{w}$ and $g_{x}$ on steady state employment can be obtained from simple log differentiation of (4) to obtain,

$$
\Delta \ln L^{*}=\varepsilon \cdot \Delta \ln \alpha
$$

where $\varepsilon$ is the steady state elasticity of labor supply with respect to the wage,

$$
\varepsilon=\alpha \rho \frac{\Omega^{\prime}(\alpha \rho)}{1-\Omega(\alpha \rho)} .
$$

It is important to note that $\varepsilon$ is the elasticity of labor supply on the extensive margin, i.e. the employment vs. nonemployment margin. Consequently, it measures the elasticity of the inverse c.d.f. of reservation wages in the economy.

Thus, we see that the employment effects of changes in the rates of aggregate wage growth

and the return to experience are increasing in the size of the wage - elasticity of aggregate labor supply, $\varepsilon$. The intuition for this result is simple. A small value of $\varepsilon$ implies that there are little incentive effects of wages on workers' choice to supply labor. This in turn extinguishes the labor supply effects of wage growth which rely on the notion that wages incentivize labor supply.

It is natural to ask what factors might determine the size of the employment elasticity. We now show that $\varepsilon$ will be particularly large for workers who are low-skilled. To see this, note that we can write the steady-state employment rate among workers of a given skill $\omega$ 


$$
L^{*}(\omega)=1-\Lambda(\alpha \rho / \omega)
$$

where $\Lambda(\cdot)$ is the c.d.f. of the inverse of workers' idiosyncratic payoffs from not working, $1 / \beta_{i}$. It follows that the wage elasticity of the employment rate for workers of skill $\omega$ is equal to

$$
\varepsilon(\omega)=\frac{\alpha \rho}{\omega} \frac{\Lambda^{\prime}(\alpha \rho / \omega)}{1-\Lambda(\alpha \rho / \omega)} .
$$

It is straightforward to verify that a sufficient condition for this elasticity to decline with skill, $\omega$, is that the modal worker of that skill is employed. ${ }^{4}$ Thus, the model predicts that low-skilled workers respond to changes in the rate of aggregate productivity growth and the return to experience to a greater extent. The simple reason is that low-skilled workers are more likely to be on the margin of the employment decision than high-skilled workers, and therefore are more responsive to changes in the incentives to work.

This prediction of the model formalizes the intuition underlying the empirical analysis of Juhn, Murphy, and Topel $(1991,2002)$. They show that much of the increase in joblessness in the U.S. from the 1970s onward is concentrated among low-skilled workers, an observation that is replicated in Figure 1B. In addition, they provide estimates of the elasticity of labor supply by skill group (see Table 9 of their 1991 article and Table 10 of their 2002 article) that confirm that low-skilled labor supply is much more elastic than for higher skilled workers. Both of these results are consistent with the formal implications of our model. We will see later in Section IV that the tight correspondence between our theoretical model and the empirical results of Juhn, Murphy, and Topel will enable to us to interpret and quantify the implications of our model for observed trends in joblessness in the U.S. over time.

\footnotetext{
${ }^{4}$ To see this, note that since $\alpha \rho / \omega$ is declining in $\omega$, the elasticity of aggregate labor supply for workers with skill $\omega$ will decline with skill if $\Lambda^{\prime \prime}(\alpha \rho / \omega)>0$. If $\Lambda(\cdot)$ is unimodal, a sufficient condition for the latter is that the modal worker with skill $\omega$ chooses to work.
} 


\section{Summary of Qualitative Predictions}

This section has used a very simple model to elucidate the effects of wage growth on aggregate employment in an environment that incorporates a return to labor market experience. It has established the following qualitative predictions:

- Increases in the rate of return to experience reduce reservation wages and stimulate aggregate employment by increasing the present discounted value of working over not working.

- If there is a positive return to experience, increases in the rate of aggregate wage growth will also reduce reservation wages and raise aggregate employment.

- The employment effects of wage growth, of the return to experience, and of the interaction of wage growth and the return to experience will be greatest among low-skilled workers who are the most marginal to the employment decision.

\section{Evidence}

The preceding section has provided a rationale for why changes in experience-earnings profiles and aggregate wage growth that workers face can have implications for changes in aggregate employment. In the light of this, in this section we take on the task of documenting evidence on changes in the returns to experience and in aggregate wage growth by skill for workers in the U.S. over time. In Section IV, we use this evidence, together with a generalization of the model of Section II, to simulate the effects on employment rates of changes in the return to experience and its interaction with real wage growth. 


\section{A Changes in the Experience-Earnings Profile by Skill}

To measure changes in the experience-earnings profile over time, we employ data taken from the decennial Censuses from 1960 to 2000, and the American Community Surveys from 2001 to 2007 for the U.S. ${ }^{5}$ Earnings are measured by the annual wage, salary and business income of respondents. As our theory makes clear, we are especially interested in changes in returns to experience for marginal workers who are relatively low in the skill distribution. We use educational attainment as a proxy measure of skill. We distinguish among high school dropouts (9 to 11 years of education), high school graduates (12 years), those with some college education (13 to 15 years) and those with a college or higher degree (16+ years). Experience is measured by potential experience, i.e. age minus years of education minus six.

We additionally restrict our samples along several dimensions. First, we concentrate on outcomes for white men since labor force participation issues for non-whites and women are significantly more complicated (Smith and Welch, 1989; Welch, 1990; Blau, 1998). ${ }^{6}$ In particular, we restrict the samples to non-immigrant white males aged 16 to 64 . Second, we focus on the return to experience among full-time, full-year workers, defined as those who work 35 hours or more per week, and who are employed for 50 or more weeks per year. We do this for a number of reasons. By focusing on such workers, we can be more confident that respondents have left full-time education when we observe their earnings. Moreover, the observed profiles are more likely to reflect variation in wages rather than hours or weeks worked. Finally, as will become clear in what follows, the fact that we are able to measure only potential experience raises a concern that a changing relationship between potential and actual experience could confound observed changes in experience-earnings profiles. By

\footnotetext{
${ }^{5}$ Our Census samples are taken from the public use 1\% sample for 1960, $2 \%$ sample for 1970 , and $5 \%$ samples for 1980 to 2000 available from IPUMS. They parallel those used by Heckman, Lochner, and Todd (2007) in their important study of the returns to schooling. We are grateful to those authors for providing us with detailed tabulations from their work that we used in the preliminary version of this paper.

${ }^{6}$ These are worthy topics that warrant careful and separate analyses. For an analysis of the employment effects of changes in returns to experience among women, see Olivetti (2006).
} 
concentrating on full-time, full-year workers, such a confound is minimized.

Figure 2 plots average log earnings as a function of potential experience by education group, normalized to the mean log earnings of workers entering the labor market. Log earnings are normalized to equal zero at zero experience to abstract from the significant differences in levels of earnings across education groups and of aggregate wages across time. Within each panel, the lines correspond to the experience-earnings profiles for different Census years for a given education group. ${ }^{7} \quad$ Figure 2A displays the experience earnings profile for high school dropouts (9-11 years of education) over time. Note that outcomes for these lower-skilled workers are of particular interest for our purposes because they are more likely to be marginal to the employment decision. Figure 2A tells a striking story: The experience-earnings profile among high school dropouts flattened dramatically after 1970. At five to ten years of potential experience, earnings are around $50 \log$ points lower in the later period compared to the earlier period. In addition, the gap in the experience-earnings profile persists at higher levels of experience.

Figure 2B plots the experience profile for high school graduates. This reveals a mild drop in mid-career earnings between 1970 and 1990, with a more substantial drop in the experience earnings profile between 1990 and 2000. In comparison to the outcomes for high school dropouts, the changes are relatively modest.

As emphasized above, workers with schooling beyond high school are unlikely to be at the point in the skill distribution where employment is a marginal decision, so that patterns in experience-profiles among these groups are less relevant to employment rates. By way of comparison, however, we include results in Figures 2C and 2D for workers with some college education and a college degree or higher respectively. For these higher skilled workers, an

\footnotetext{
${ }^{7}$ Prior to 1980, Census data record only hours last week, and after 1990 only usual hours of work. Reacting to this, we impose the full-time restriction for the 1960 to 1990 profiles based on hours last week. After 2000, we compute the difference in the experience-earnings profile generated by implementing the full-time restriction using these alternative hours measures in 1990, when both measures are available. We then apply that difference to impute the experience-earnings profiles from 2000 on.
} 
opposite trend can be discerned, especially for college educated workers, with experienceearnings profiles steepening over time.

A question that arises in the light of the substantial decline in the experience-earnings profile for high school dropouts in Figure $2 \mathrm{~A}$ is how big a reduction this is. A natural way to quantify the decline is to compute the capitalized value of the earnings streams illustrated in Figure 2A. Figure 3 performs this exercise. It plots the capitalized value of the experienceearnings profiles in Figure 2A, normalized to equal 100 in 1970, for a range of values for the discount rate. A clear picture emerges: Regardless of the discount rate, the value of the experience-earnings profile for high school dropouts declined by almost 50 percent between 1970 and 2007, a substantial reduction.

Synthetic vs. Actual Cohorts The preceding results report cross-sectional experienceearnings profiles at given points in time. For the purposes of our analysis of the likely employment effects of any changes in these profiles, we would like to obtain information on workers' expectations of their likely experience profile at the time that they are making their labor supply decisions. It is likely that these cross-sectional profiles are informative to some degree on these expectations - for instance, if workers have static expectations or changes are permanent, so that static expectations are rational.

An alternative way of slicing the data, however, would be to plot the realized experienceearnings profiles of individual cohorts. This alternative approach would be consistent with workers' expectations if they were endowed with perfect foresight. The truth, of course, is likely to lie somewhere between these two extremes, so it is natural to check whether the basic message of the data changes by shifting perspective in this way.

Figure 4 presents the realized experience-earnings profiles for the cohorts entering the labor market in 1960, 1970, 1980, 1990, and 2000. Since the Census data we use is available only at a decadal frequency, we plot earnings for members of these cohorts every 10 years. ${ }^{8}$

\footnotetext{
${ }^{8}$ Additionally, we impute data points for 2010 under the assumption that the experience-earnings profile
} 
For high school dropouts, the picture by cohort in Figure 4A tells exactly the same story as the cross-sectional picture in Figure 2A. Wage growth declines for each consecutive cohort entering the labor market after 1960, and the declines are of similar magnitude as those indicated by the cross-sectional profiles in Figure 2A. Likewise, the cohort profiles for high school graduates, and those with college education in Figures 4B, 4C and 4D echo the patterns observed in their cross-sectional counterparts in Figure 2. Most noticeably, it is again possible to discern a steepening of experience-earnings profile among younger cohorts of college graduates. It is reassuring that these two different slices of the data have similar implications. Since these two approaches have the same message, we use the cross sectional results of Figure 2 for the simulations in Section IV.

Potential vs. Actual Experience As hinted at earlier, an important potential confound to the evidence presented in Figures 2 and 4 is that we observe only potential, not actual experience in the data. A particular cause for concern is that the declines in employment rates among high school dropouts noted in Figure 1 have led to a widening of the gap between potential and actual experience among this group of workers. Consequently, it is possible that this could account for some of the flattening of the observed relationship between mean $\log$ earnings and potential experience in Figures $2 \mathrm{~A}$ and $4 \mathrm{~A}$, as older workers with high potential experience increasingly accumulate fewer years of actual experience, and thereby earn less.

Reacting to this, we perform a simple exercise that we believe provides an upper bound on the magnitude of this effect. Specifically, imagine, counterfactually, that employment is i.i.d. across workers at any given point in time. In steady state, this will imply that the actual experience of a worker is simply equal to the employment rate multiplied by potential experience. It follows that, in this environment, accounting for the difference between potential and actual experience amounts simply to a rescaling of the horizontal axis in 2010 will be the same as that in the pooled 2001 to 2007 ACS samples. 
in Figure 2A, by a proportion equal to the employment rate. To see why such an exercise provides an upper bound for the magnitude of these effects, note that employment is not i.i.d. across workers, but is rather a persistent process. In particular, by focusing on fulltime, full-year workers we are considering workers who are more than averagely attached to the labor market.

Figure 5 presents the results of this exercise. It illustrates the potential experienceearnings profiles from Figure 2A for 1970 and 2000, as well as the implied actual experienceearnings profiles that would obtain by rescaling the horizontal axis by the trend employment rates in 1970 and 2000 respectively. ${ }^{9}$ Figure 5 shows that, although some of the flattening of the experience - earnings profile can be accounted for by a widening gap between potential and actual experience, the magnitude of these effects is likely to be small. Even after accounting for an upper bound on these effects, after five to ten years of experience earnings remain around 45 log points lower in 2000 compared to 1970. In Appendix B, we report estimates of the difference between potential and actual experience among high school dropouts over time using the Panel Study of Income Dynamics. These estimates confirm that the exercise underlying Figure 5 is likely to be an upper bound.

Selection Additional potential confounds that may affect our finding of a flattening of the experience-earnings profiles among high school dropouts relate to forms of selection that vary over time. We highlight two of these possibilities here. First, since the fraction of each cohort of workers that are high school dropouts has fallen over time, it is natural to conjecture that dropouts have become increasingly lower skilled over time. An implication of this would be that, at any given point in time, measured experience-earnings profiles among dropouts would overstate the return to experience, since older dropouts are of higher quality

\footnotetext{
${ }^{9}$ The trend employment rates used are 10 percent and 25 percent for 1970 and 2000 respectively (see Figure 1). More complicated corrections that relax the steady state assumption and account for time variation in employment rates that workers of different levels of potential experience have faced in their working lives yield very similar pictures.
} 
than their younger counterparts for a reason unrelated to their accumulation of experience. Thus, selection of this sort could lead to a spurious flattening of the experience profile if the dropout rate were to fall over time at a decreasing rate.

Recent research suggests that this is unlikely to be a concern over the sample period. In fact, the notion that high school dropouts have become increasingly lower skilled over time receives little support in careful analyses of graduation rates in the U.S. Heckman and LaFontaine (2007) demonstrate that most of the decline in headline dropout rates among white males (e.g. from the National Center of Education Statistics) can be attributed to increases in the fraction of GED recipients in successive cohorts. In addition, Heckman and Rubinstein (2001) and Heckman and LaFontaine (2006) argue that, while such GED recipients exhibit similar cognitive ability to high school graduates, their labor market outcomes mirror those of high school dropouts. This suggests that compositional changes related to increased take up of the GED are unlikely to explain our results for dropouts. ${ }^{10}$

A second potential form of selection can arise if there are heterogeneous returns to experience across workers. In such an environment, one would expect individuals with high returns to labor market experience to be more likely to choose to work. Since the experienceearnings profiles in Figure 2 depict the average returns to experience among those that choose to work, it is likely that they overstate the average return to experience among the entire working and non-working population.

This source of selection may also vary over time. As employment rates fall among high school dropouts, the measured return to experience that we observe will report the average returns for an increasingly select group of workers. Consequently, we would anticipate this form of selection to lead us to observe a steepening of experience-earnings profiles, as the only workers who choose to work will be those with increasingly higher returns to experience.

\footnotetext{
${ }^{10}$ Although high school dropouts are our main focus, it is worth noting that the grouping of individuals with a GED qualification with high school graduates may lead to some spurious steepening of the measured experience-earnings profile for high school graduates. This would tend to work against our ability to account for increases in nonemployment among high school graduates.
} 
Comparison with Previous Literature The evidence presented in Figure 2 is not the first to look at changes in returns to experience by skill. A number of studies in the literature on wage inequality has estimated the "experience premium," measured as the log wage gap between experienced workers (typically with 25 years of experience) and less experienced workers (5 years of experience) using Current Population Survey data (see, for example, Katz and Murphy, 1992; Weinberg, 2005; Autor, Katz and Kearney, 2008). These studies all have documented evidence for a rise in the experience premium among high school graduates and college graduates over time.

A natural question, then, is whether the evidence presented in Figure 2 using Census and ACS data is consistent with the results of these previous analyses using CPS data. Figure 6 addresses this question by plotting the experience premium by education group across time using the Census/ACS underlying Figure 2, as well as for comparable CPS samples.

The picture painted in Figure 6 is a relatively reassuring one: Despite some differences in the measured levels of the experience premium in the two different sources of data, the trends in the experience premium by skill are consistent over time. ${ }^{11}$ As reported in the above-cited studies, the experience premium among high school and college graduates has trended upward over time in both the CPS and Census/ACS samples we use. However, consistent with the impression in Figure 2A that the experience-earnings profile for dropouts has flattened over time, the experience premium among high school dropouts has trended downward since 1970 in both data sources. Thus, our empirical works confirms earlier findings in the literature that the return to experience for workers who have at least a high school education have enjoyed an increase in the return to experience. Our work has the new and important finding, however, that the workers with the lowest educational attainment have faced a decrease in the returns to experience.

\footnotetext{
${ }^{11}$ While the $25 / 5$ experience premium is a commonly used measure, the high frequency movements observed in the CPS estimates should be treated with caution due to the low sample sizes available in the CPS. The standard errors around each datapoint in Figure 6 averaged 0.16 for dropouts, 0.09 for high school graduates, 0.12 for some college, and 0.14 for college graduates.
} 


\section{B Changes in Aggregate Wage Growth by Skill}

We now turn to observed changes in the rate of aggregate wage growth by skill. The measures that we present are based on data from the March Current Population Survey microdata for the period 1967 to 2006. We focus our sample on non-immigrant white males aged 16 to 64 with fewer than 30 years of potential experience who report that they were out of school for the entire year and are not self-employed. ${ }^{12}$ Wages are measured by dividing annual wages and salary by annual hours worked. Mirroring our analysis of experience profiles, we again proxy skill using discrete education categories: high school dropouts (9 to 11 years), high school graduates (12 years), some college (13 to 15 years), and college degree or higher $(16+$ years $) \cdot{ }^{13}$

Figure 7 plots trend hourly wage growth by education from 1968 through to 2006 based on these CPS samples. Specifically, this takes estimates of real hourly wages by education, computes implied annual wage growth by education, and reports the HP filtered series. This exercise reveals a clear picture of aggregate wage growth in recent decades: For all educational groups, aggregate wage growth fell in 1970s, rebounded in the 1980s and 1990s, and has fallen off again in recent years. In addition, we observe that trend wage growth declined more acutely among low-skilled workers in the 1970s. Among high school dropouts, wage growth declined secularly in the 1970s from around 3 percent per year to trend real wage declines of approximately 3 percent in late 1970s and early 1980s. In contrast, real wage growth among college educated workers declined more slowly in the 1970s, and rebounded more robustly in the 1990s. ${ }^{14}$

\footnotetext{
${ }^{12}$ These sample restrictions parallel those in Juhn, Murphy and Topel's (1991, 2002) influential analyses of wages and employment by skill in the U.S.

${ }^{13}$ Juhn, Murphy and Topel $(1991,2002)$ measure skill by percentiles of the wage distribution, rather than by educational groups. Reassuringly, they obtain similar results.

${ }^{14} \mathrm{~A}$ potentially important confound to the trends in Figure 7 is the growth of non-wage compensation (such as health insurance, pensions and paid leave) that emerged over the period. It is difficult to get an accurate sense of this from the data sources we use. However, using the microdata underlying the Employment Cost Index, Pierce (2001) shows that wage growth understated compensation growth among high-skilled workers in the 1980s, but that it overstated compensation growth among the low-skilled in the 1990s. Hence, for total compensation the relative growth rate in wages for low-skilled workers is likely to
} 
These observations echo well-documented facts on aggregate growth, as well as wages by skill. The secular decline and subsequent rebound in aggregate wage growth over time mirrors the productivity slowdown of the 1970s as well as the so-called "productivity miracle" of the 1990s in the U.S. Figure 7 overlays the trend productivity growth rate over the same period to emphasize these trends. Likewise, the observation that wage growth declined more sharply among the low-skilled in the late 1970s and 1980s is consistent with the widely documented increase in wage inequality that emerged over that period.

\section{Quantitative Implications}

The preceding sections have outlined a number of key results. Section II showed that, in a labor market with positive returns to experience, there are good reasons to expect that changes in experience-earnings profiles and aggregate wage growth will have important ef-

fects on equilibrium rates of employment. In addition, Section II emphasized that such effects are likely to be strongest among low-skilled workers who are marginal to the employment decision. Then, in section III, we documented strong evidence for a decline in the experience-earnings profile of high school dropouts. In addition, we provided evidence for substantial declines in aggregate wage growth in the 1970s and 1980s, which were particularly acute for low-skilled, marginal workers.

A natural question in the light of these results is what the likely effects are of the observed changes in experience earnings profiles and aggregate wage growth on the aggregate rates of nonemployment documented in Figure 1. Section II provided a simple qualitative model of these effects. To get a sense for the magnitude of the implied effects, we now analyze a more general model of labor supply in the presence of returns to experience.

be even less favorable than shown in Figure 7 . 


\section{A A More General Model}

The model of the Section II is simplified in a number of respects. In this section we relax some of these simplifying assumptions. First, we allow for finite worker lifetimes. This enables discussion of the differential effects of changes in wage growth across different cohorts of workers in a natural way. Second, we allow the return to experience to be nonlinear to allow for the concavity of the experience-log earnings profile observed in Figures 2 and 4. This allows us to match the experience-earnings profile in the model with that observed in the data. Third, we allow workers to choose whether to work or not at all times in their lives, thereby relaxing the once-and-for-all labor supply decision of Section II. We will see that extending the model in this manner will allow us to draw out the dynamic effects of changes in rates of wage growth on employment in and out of steady state. Though more realistic, we will see that these changes do not change the basic qualitative message of the simple model of Section II.

Consider a worker entering the labor market at time $s$ with a working life of length $T$. At each point in time the individual chooses whether he wants to work $(h=1)$ or not work $(h=0)$. As in the model of Section II, for every year he works, he accumulates a year of labor market experience, $x$; he does not accumulate experience while not working. A worker of experience $x$ at time $t$ receives a flow wage equal to $w(x, t) .{ }^{15}$ An individual who does not work at time $t$ receives a flow payoff $b(t)$. The worker makes his labor supply decision in order to maximize the present discounted value of his lifetime income.

Thus, we can state the optimization problem of an individual entering the labor market at time $s$ as follows:

$$
\max _{h(t)} \int_{s}^{s+T} e^{-r(t-s)} y(x, t, h) d t \text { s.t. } \dot{x}=h, h \in\{0,1\}, x(s)=0
$$

where $r$ is the real interest rate. The individual's income at time $t$ is given by $y(x, t, h)=$

\footnotetext{
${ }^{15}$ In this more elaborate model, we suppress the $i$ subscript that indexes individuals for purposes of clarity.
} 
$h w(x, t)+(1-h) b(t)$. If the individual works $(h=1)$ he receives the wage; otherwise, he receives the payoff from not working. The first constraint in (9) regulates the accumulation of experience over the worker's lifetime such that experience is accumulated only when the individual works. The second emphasizes our focus on the extensive margin of the labor supply decision. And the third constraint states the initial condition that new entrants into the labor market enter with no accumulated experience.

The maximization problem in equation (9) can be restated more simply as an optimal control problem with associated Hamiltonian

$$
H(x, t, h, \lambda)=h w(x, t)+(1-h) b(t)+\lambda h .
$$

Note that the Hamiltonian is linear in the labor supply variable, $h$. It follows that an individual with experience $x$ at time $t$ will work if the wage offer $w(x, t)$ exceeds a reservation wage given by

$$
w_{R}(t)=b(t)-\lambda(t)
$$

where we will see that $\lambda(t) \geq 0$. Thus, just as in the simple model of Section II, we observe that the reservation wage lies below the flow payoff from nonemployment. As before, individuals are willing to forgo payoffs in the short run in order to reap the returns to experience in the long run.

To characterize the reservation wage more precisely, however, we must describe the variable $\lambda$ in more detail. Using the principles of optimal control, it is simple to show that $\lambda$ can be expressed as ${ }^{16}$

$$
\lambda(t)=\int_{t}^{s+T} e^{-r(\tau-t)} h(x(\tau), \tau) w_{x}(x(\tau), \tau) d \tau .
$$

\footnotetext{
${ }^{16}$ From the principles of optimal control, we can write $\dot{\lambda}=r \lambda(t)-\partial H / \partial x=r \lambda(t)-h(x, t) w_{x}(x, t)$. The solution to this differential equation is given in equation (12). The constant of integration is equal to zero because of the transversality condition that $\lambda(s+T)=0$.
} 
Thus, $\lambda$ has a very intuitive interpretation. It is the cumulative discounted sum of future returns to experience, $w_{x}(x(\tau), \tau)$, taking into account that these future returns accrue only in the event that the individual works in the future $(h(x(\tau), \tau)=1)$. In short, $\lambda$ is the marginal value of experience to a worker.

This simple interpretation in turn delivers a simple interpretation of the reservation wage. In particular, we can rewrite the reservation wage as

$$
w_{R}(t)=b(t)-\int_{t}^{s+T} e^{-r(\tau-t)} h(x(\tau), \tau) w_{x}(x(\tau), \tau) d \tau
$$

Thus, the reservation wage is equal to the flow benefit from not working, $b(t)$, less the opportunity costs of not working, which equals the foregone returns to experience. As stated, the reservation wage is a very forward looking object - it depends on the entire sequence of future labor supply decisions from time $t$ until the end of the individual's life, $s+T$. To obtain a more concrete sense of the form of the reservation wage, we need to partition the individual's remaining lifetime into episodes allocated respectively to employment and nonemployment. This is aided by the following result:

Proposition 1 If $(i) r-g_{w}>0$, so that workers discount the future; $(i i)$ the experienceearnings profile is monotonically increasing, ${ }^{17}$ and $($ iii) there are no shocks, then a worker who decides to work at time $t$ subsequently will work for the remainder of his working life.

Intuitively, consider an individual who is just about to start working. By definition, such an individual only just prefers working over not working. As the individual works, however, he accumulates human capital which in turn serves only to make employment increasingly preferable relative to not working. As a result, the individual continues to work until he

\footnotetext{
${ }^{17}$ Assuming that $w_{x}(x, t)>0$ for all $x$ and $t$ is not entirely innocuous. Evidence suggests that average real wages can decline with experience at the end of a worker's career. However, it is not clear whether this is driven by (partial) retirement. For the horizons we focus on in what follows (the first forty years of working life) this is not such a bad assumption. An extension of the model to account for optimal retirement would be an interesting topic for future research.
} 
retires.

In the light of this, we adopt the convention that, whenever the individual is offered his reservation wage, he works thereafter. It follows that, for an individual with experience $x$ at time $t$, we can substitute $h(x(\tau), \tau)=1$ and $x(\tau)=x+\tau-t$ for all $\tau>t$ into the reservation wage equation above to derive

$$
w_{R}(x, s, t)=b(t)-\int_{t}^{s+T} e^{-r(\tau-t)} w_{x}(x+\tau-t, \tau) d \tau
$$

To complete our characterization of the reservation wage, we must be more explicit about the form of the wage equation. Denoting aggregate wage growth by $g_{w}$, and the return to experience at $x$ years of experience as $g_{x}(x) \equiv \partial \ln w(x, \tau) / \partial x$ allows one to write

$$
\begin{aligned}
& w_{R}(x, s, t)=\alpha(x, s, t) b(t) \\
& \text { where } \alpha(x, s, t)=\left[1+\int_{t}^{s+T} e^{-\int_{t}^{\tau}\left[r-g_{w}-g_{x}(x+z-t)\right] d z} g_{x}(x+\tau-t) d \tau\right]^{-1}
\end{aligned}
$$

Although the form of the reservation wage in this more general model does not appear straightforward, a number of observations can be made in the light of it. First, note that the reservation wage takes a form that is reminiscent of equation (4) from the simple model of Section II: The reservation wage is equal to the flow payoff from not working $b(t)$, scaled down by a factor $\alpha(x, s, t) \leq 1$. As emphasized before, workers are willing to forgo current earnings to reap the returns to experience in the future. The return to experience drives a wedge $\alpha(x, s, t)$ between the payoff from nonemployment and the reservation wage.

Second, note that in the case where individuals are infinitely lived, $T \rightarrow \infty$, and the return to experience is constant for all levels of $x, g_{x}(x) \equiv g_{x}$, then $\alpha(x, s, t) \rightarrow 1-\left[g_{x} /\left(r-g_{w}\right)\right]=\alpha$ from equation (4). Thus, the general model nests the simple model of Section II as a special case. $^{18}$

\footnotetext{
${ }^{18}$ Note also that the once-and-for-all labor supply assumption in the simple model of Section II is therefore not a binding one. This, of course, follows from Proposition 1.
} 
In addition, we again observe that changes in the experience-earnings profile, summarized by $g_{x}(\cdot)$, and aggregate wage growth, $g_{w}$, affect the reservation wage. As before, increases in the experience-earnings profile and aggregate wage growth reduce $\alpha(x, s, t)$, thereby lowering the reservation wage and stimulating work incentives. The difference in equation (15) is that, by taking into account finite lifetimes and concave experience earnings profiles, the magnitudes of these effects are likely to be more sensible.

A final key message of equation (15) is the implied life-cycle effects of changes in $g_{x}(\cdot)$ and $g_{w}$. Specifically, the marginal effects of these changes on the reservation wage are stronger for younger cohorts at a given point in time $t$ and weaker for older cohorts. To see this, consider equation (15) and recall that $s$ denotes time of entry into the labor market, so that higher values of $s$ refer to younger cohorts. Mechanically, this result arises because older workers have a shorter remaining working life over which changes in wage growth of any variety can affect the present value of their remaining earnings stream. More intuitively, as workers age, they become increasingly less marginal to the employment decision, and consequently respond less to changes in wage growth. ${ }^{19}$ We will see in what follows that these life-cycle effects have distinctive implications for the dynamics of employment generated by the model.

\section{B Implications for Low-Skilled Joblessness}

The results of Section III documented evidence for reductions in the return to labor market experience for low-skilled, marginal workers since 1970, as well as important changes in aggregate wage growth for such workers over the same period. We now seek to provide a quantitative sense of the implications of these trends for work incentives and equilibrium employment. To do this, we feed the observed trends in the experience-earnings profile and aggregate wage growth into a simulated version of the general model summarized in equation

\footnotetext{
${ }^{19} \mathrm{By}$ the same token, it is also true that the reservation wage coefficient $\alpha(x, s, t)$ is larger for older cohorts. One might imagine that this reduces work incentives for older workers. However, we know from Proposition 1 that any individual who starts working will work until retirement. The reason is the wage growth that workers receive as they accumulate experience.
} 
(15). Since the trends in the aggregate nonemployment rate are driven by the increase in nonemployment among low-skilled workers, we focus on generating the implied outcomes for high school dropouts.

We set the length of a working life to 40 years, and initialize the model in steady state in 1970. We set the initial steady-state employment rate to equal 90 percent based on the observed trend nonemployment rate for high school dropouts in 1970 (see Figure 1B). We then compute the implied paths of the employment rate for each experience $x$, cohort $s$ and time $t$ configuration by extending the simple insight of equation (5):

$$
\Delta \ln L(x, s, t)=\varepsilon \cdot \Delta \ln \alpha(x, s, t),
$$

where variation in the reservation wage coefficient $\alpha(x, s, t)$ is induced by variation in aggregate wage growth $g_{w}$ and the experience-earnings profile $g_{x}(\cdot)$. Finally, we aggregate across $(x, s, t)$ cells to compute the path of aggregate employment, $L(t)$.

Our simulation procedure therefore reduces the problem down to finding a value of $\varepsilon$, the elasticity of labor supply. Recall from our earlier discussion that, for our purposes, $\varepsilon$ is the elasticity of labor supply on the extensive margin - the elasticity of the inverse distribution function of reservation wages (see equations (6) and (8)). Estimates of $\varepsilon$ for different skill groups are reported by Juhn, Murphy and Topel (1991, 2002). Specifically, they compute estimates of the elasticity of the fraction of a year spent in employment with respect to wages by skill using Current Population Survey data. As mentioned in our discussion of trends in aggregate wage growth in section III.B, Juhn, Murphy and Topel measure skill by ranges of percentiles of the wage distribution. ${ }^{20}$ Since high school dropouts lie in the bottom 20 percent of the education distribution, Juhn, Murphy and Topel's estimates suggest that a

\footnotetext{
${ }^{20}$ To do this, Juhn, Murphy and Topel $(1991,2002)$ estimate the wage offers of those out of employment. They do this by imputing wages to nonworkers using the distribution of wages among individuals who worked between 1 and 13 weeks in a given year.
} 
reasonable value of $\varepsilon$ is approximately $0.33 .^{21}$

It is worth noting that our simulation strategy has a number of virtues. First, by reducing the procedure down simply to obtaining a value for $\varepsilon$, we have avoided having to explicitly calibrate variables such as the replacement rate $\rho$, or the distribution of worker heterogeneity $\Omega(\cdot)$ in equation (3). Since we might be less confident in the correct calibration of these objects, this is a useful simplification. In addition, the simulation strategy is very transparent. If one has different priors about the appropriate value for the supply elasticity $\varepsilon$, all one need do is scale the implied employment effects up or down accordingly. For example, if one believed $\varepsilon$ were double the value we use, then the implied employment effects will be double what we report.

A Simple Example To get a sense for the dynamic response of aggregate employment implied by the model, we first consider the effects of a very simple shock. Figure 8 plots the response of aggregate nonemployment to a one-time, permanent, unanticipated decline in aggregate wage growth $g_{w}$ from 3 percent (as observed in the early 1970s among dropouts) to -3 percent (as observed in the mid 1980s among dropouts). The dashed line plots the steady state nonemployment rate before and after the shock. This rises substantially from 10 percent to approximately 20 percent.

The response of the nonemployment rate out of steady state, however, reveals important transitional dynamics in the model. On impact, a discrete fraction of workers immediately leaves employment, deciding that the reduction in lifetime earnings renders working no longer worthwhile. Subsequently, the nonemployment rate exhibits very slow transitional dynamics, eventually reaching the new steady state after 40 years. These transitional dynamics are a direct consequence of the life-cycle response to shocks emphasized in the general model

\footnotetext{
${ }^{21}$ Table 10 of their 2002 Brookings paper reports partial elasticities (i.e. the change in employment divided by the log change in wage) by skill percentiles for the years 1972 to 2000 . For the 1st to 10th percentile, their estimate of the partial elasticity is 0.287 ; for the 11 th to 20 th percentile, 0.217 . These imply elasticities of approximately 0.39 and 0.27 respectively. Our choice of $\varepsilon=0.33$ is an approximate midpoint of these estimates.
} 
above. As workers age, they become increasingly less marginal to the employment decision, and thereby become less responsive to shocks. What is driving the dynamics in Figure 8 is the turnover of successive cohorts in the labor market as older cohorts retire, and younger, more marginal workers enter. It is therefore no surprise that the period of transition is exactly 40 years, the specified length of a working life, since that is the time it takes for all older cohorts at the time of the shock to leave the labor market.

Simulation Results We can now address the question of the effects of observed changes in the experience-earnings profile and aggregate wage growth for rates of nonemployment among high school dropouts. We match the return to experience in the model, $g_{x}(\cdot)$, to smoothed versions of the cross-sectional profiles for high school dropouts in Figure 2 A. ${ }^{22}$ Aggregate wage growth in the model, $g_{w}$, is matched to trend wage growth among high school dropouts based on the estimates in Figure 7. We then feed these trends into the model as a series of unanticipated shocks. Figure 9 displays the results of this exercise, together with the trend nonemployment rate among high school dropouts from Figure 1B for comparison.

The model predicts a substantial rise in the nonemployment rate for low-skilled workers. Figure 9 reveals that the joint trends in $g_{x}(\cdot)$ and $g_{w}$ together imply an increase in low-skilled nonemployment from 10 percent to 24 percent between 1968 and 2006. Comparing these outcomes to the observed trend from the data, this suggests that the model can account for most of the secular rise in nonemployment among high school dropouts over this period. Thus, variation in the returns to experience together with changes in the rate of aggregate wage growth have the potential to go a long way toward explaining the long-run variation in nonemployment for low skilled workers in the context of this model.

However, Figure 9 also suggests that the model is less successful in matching the observed

\footnotetext{
${ }^{22}$ In practice, a specification that relates log earnings to a power function in experience provides a good fit.
} 
timing of the increase in trend nonemployment among high school dropouts. The data reveal a substantial medium run rise in nonemployment in the 1970s and 1980s that the model does not fully predict. This may partly be due to our choice to feed variation in $g_{x}(\cdot)$ and $g_{w}$ through the model as unanticipated shocks. It is possible that some of these changes may eventually have been anticipated. For example, workers may have become wise to the downward trend in aggregate wage growth seen in Figure 7 . This would speed up the response of nonemployment to these shocks.

More generally, we do not necessarily view the model's inability to predict the medium run rise in joblessness as a problem, as it provides room for other explanations to play a role. Most notably, Juhn, Murphy and Topel's (1991, 2002) suggestion that the decline in demand for low-skilled workers associated with the increase in wage inequality that occurred in the 1970s and 1980s played an important role could account for the sharp rise in joblessness in the 1970 s and 1980s.

Figure 9 also plots the implied trends in nonemployment from allowing the return to experience and aggregate wage growth to vary independently. This suggests that, between 1968 and 2006, changes in aggregate wage growth and experience-earnings profiles accounted for about an equal share of the implied increase in low-skilled nonemployment in the model. However, it also reveals that the effects of $g_{w}$ are relatively more important earlier on, whereas the return to experience plays more of a role later on. This is consistent with the trends

depicted in Figures 2A and 7. Declines in aggregate wage growth occur predominantly in the early part of the sample period, whereas declines in the return to experience among dropouts occur much more uniformly over the period.

\section{Implications for the Age Distribution of Joblessness}

As a final check on the implications of our model, we also explore the implied age structure of the rise in nonemployment. We do this because our model has distinctive life-cycle predic- 
tions. Specifically, recall that the model implies that older workers become less responsive to wage growth shocks, because such shocks have a smaller relative impact on their remaining lifetime earnings. It follows that the shocks that we observe in the data are predicted to have a more immediate impact on the employment rates of younger workers relative to older workers.

To examine this possibility, we partition workers in our simulated model into those who have lived fewer than twenty years of their working life, and those who have lived more than twenty years. Figure 10A plots the nonemployment rates for each of these groups predicted by the model. Consistent with our intuition, we observe the nonemployment rate for younger workers rising earlier and faster than that for older workers. Eventually, these converge as older workers increasingly have responded to the deterioration of wage growth in the past.

Figure 10B plots the analogous picture using data from the Current Population Survey. It displays the trend nonemployment rates for workers above and below the age of 40 . The qualitative picture presented in Figure 10B is remarkably similar to the model's predictions in Figure 10A. The nonemployment rate among younger workers rises earlier and faster than for older workers. And the nonemployment rates converge in the later period in a manner similar to that implied by the model. However, as we observed with the aggregate results presented in Figure 9, the timing and magnitude of the model's predicted effects are not as successful. Nonemployment rates in the data rise faster and to a greater degree compared to that implied by the model.

\section{Implications for Aggregate Nonemployment}

Up to now, we have focused on implied trends in joblessness among low-skilled high school dropouts. In this subsection, we compute implied trends in nonemployment rates for the remaining skill groups. Our simulation procedure mirrors exactly the method described for 
high school dropouts in section IV.B. For each skill group, we feed the observed changes in the experience-earnings profile and aggregate wage growth in Figures 2 and 7 through the model as a series of unanticipated shocks. The only adjustment made is for differences in the extensive elasticity of labor supply $\varepsilon$ across skill groups. The results of section II.B. lead us to expect that $\varepsilon$ declines with skill, as more skilled workers are less marginal to the employment decision. The estimates reported in Juhn, Murphy and Topel (1991, 2002) confirm this intuition. Based on those estimates, we apply values of $\varepsilon$ equal to $0.2,0.1$, and 0.066 respectively for high school graduates, those with some college education, and those with a college degree or higher. Again, note that the effects of different assumptions on the magnitude of these elasticities are simply to rescale our reported employment effects up or down respectively.

Figure 11 plots trend nonemployment rates implied by our simulations, together with trend nonemployment rates from the data. Figure 9 for high school dropouts is replicated for ease of comparison. Figure 11 suggests that observed trends in experience-earnings profiles and aggregate wage growth can account for around 5 of the 10 percentage point increase in nonemployment among high school graduates, and 3 of the 5 percentage point increase for those with some college education. Consistent with the relative stability of the experience-earnings profiles for these groups in Figure 2, the majority of the implied increase in joblessness among both groups is driven by declines in aggregate wage growth. Figure 11 also reveals that trends in either form of wage growth can explain none of the 2 to 3 percentage point increase in nonemployment among college graduates.

The results in Figure 11 also allow us to gauge the extent to which variation in wage growth can account for the increase in aggregate nonemployment depicted in Figure $1 \mathrm{~A}$. We take a share-weighted average of the simulations in Figure 11. These simulated changes in the nonemployment rates by education group aggregate to 3.4 percentage points - a little more than half of the 6 percentage point rise observed in Figure 1A. 


\section{Related Literature}

The methods and results of our analysis touch on a wide array of related literatures. First, we have shown that a distinctive feature of our model is that it generates a role for productivity growth in explaining variation in steady state employment that is absent in standard models of long run employment determination. An important implication of this is that it provides a rationale for why the declines in aggregate wage growth that accompanied the productivity slowdown of the 1970s are related to increases in rates of joblessness.

Perhaps because prevailing models tend to predict no long run employment effects of changes in productivity growth, however, a prominent feature of previous literature has been in its emphasis on the potential short run employment effects of variation in productivity growth (see among others Blanchard, 2000; Bruno and Sachs, 1985; Ball and Moffitt, 2001). A popular idea that has been pursued is that the wage demands of workers are somewhat sluggish in their response to changes in productivity growth. Blanchard (2000) has suggested that a "comprehension lag" can arise between the moment of an initial decline in productivity growth and the time that workers become aware of it. Similarly, Ball and Moffitt (2001) have emphasized the possibility of sluggish "wage aspirations" that do not adjust immediately to declines in the sustainable rate of aggregate wage growth. Both of these possibilities will lead to a short run rise in joblessness. Moreover, depending on the sluggishness of reservation wages, the short run can last a long time.

A limitation to this approach, emphasized in Blanchard (1998), is that it becomes difficult to explain very persistent declines in employment following a productivity slowdown, unless one is willing to impose extreme forms of sluggishness in reservation wages. Such a task becomes especially difficult given the observed rebound in aggregate wage growth that accompanied the productivity "miracle" of the 1990s. Models of sluggish adjustment in reservation wages would predict reductions in joblessness in the 1990s, contrary to the evidence presented in Figures $1 \mathrm{~A}$ and 1B. 
Interestingly, our model contrasts with these predictions. The results of Section IV imply that the the productivity slowdown of the 1970s led to increased joblessness over long (thirty year) horizons, rather than short horizons. Thus, while models of sluggish adjustment in reservation wages may account for the short to medium run rise in joblessness in the 1970s and 1980s, our model can account for the persistent rise in nonemployment into the 1990s. Recall that this is driven by the important employment dynamics that are emphasized when one takes into account the effects of human capital accumulation on work incentives over the lifecycle.

An important exception to the Blanchard's (2000) rule that models of the aggregate labor market "deliver, to a first order, long run neutrality of unemployment to productivity growth" are models of creative destruction (Aghion and Howitt, 1994). In such models, the productivity of a job is fixed according to the state of the art technology available upon creation of the employment relationship. In order to update productivity back to the frontier, older relationships must be severed, hence "creative destruction." A drawback to models in this vein is that they can have counterfactual predictions with respect to the effects of productivity growth on rates of worker reallocation and the level of unemployment (Blanchard, 1998). Viewed through the lens of these models, declines in productivity growth, such as the slowdown in the 1970s, imply that the rate at which jobs become obsolete slows, reducing job destruction, and thereby unemployment. In contrast to these predictions, the productivity slowdown in the U.S. was characterized by increased rates of job destruction, and increased unemployment..$^{23,24}$

A second area of related research is the adundant literature on post-schooling investment in human capital, based on the seminal work of Ben-Porath (1967) (see Weiss and Rubinstein,

\footnotetext{
${ }^{23}$ Mortensen and Pissarides (1998) emphasize that these results depend crucially on the creative destruction assumption that technological change is embodied only in newly created jobs.

${ }^{24}$ Another exception is the analysis of Manning (1990). He shows that reductions in productivity growth can lead to increased unemployment in the context of a dynamic model of union bargaining. In his model, slower productivity growth reduces the future rents from employment available to workers. Consequently, unions capture rents in the present, raising wage pressure, and increasing unemployment.
} 
2006, for a survey). Much of this literature has highlighted the implications of the joint determination of human capital accumulation and labor supply for the life cycle profiles of earnings and hours worked (Blinder and Weiss, 1976; Heckman, 1976; Ryder, Stafford and Stephan, 1976), education choice (Willis and Rosen, 1979) and the estimation of preference and technology parameters (Shaw, 1989; Lee, 2008). Perhaps most related to the present paper is the analysis of Olivetti (2006), who emphasizes the role of changes in returns to experience among women since the 1970s. In contrast to our analysis of low-skilled males, she finds evidence of steepening experience-earnings profiles among women, and identifies it as a key driving force for increased female labor force participation since the 1970s.

\section{Summary and Discussion}

Rates of joblessness among males in the U.S. have risen dramatically since the 1970s. These trends are particularly acute among the low-skilled. This paper provides an economic rationale through which changes in wage growth-both aggregate wage growth across time, and wage growth associated with the accumulation of work experience - may have an effect on work incentives. Evidence suggests that both forms of wage growth have deteriorated since the 1970s, especially among the low-skilled. Application of these trends to a model of labor supply in the presence of wage growth indicates that declining wage growth can account for much of the increase in nonemployment among low-skilled males in the U.S. since 1970.

A number of important issues arise for future work in the light of these results. First, in an economy such as the U.S. with limited social insurance mechanisms, it is natural to ask what sources of income individuals have at their disposal when they experience persistent periods out of work, as they do in available data (Juhn, Murphy and Topel, 1991, 2002). Potential sources may include income from intermittent employment spells with limited scope for human capital accumulation, and income of other household members (which may 
interact with increases in female labor market participation over time). Future study of these alternative income sources would shed important light on why employment rates among the low-skilled have been so elastic over time.

Second, the present analysis has posed the question of what the optimal labor supply response should be given the deterioration in wage growth we observe in the data. A natural question is why wage growth changed as it did. Of particular interest is why the experienceearnings profiles among male high school dropouts flattened since the 1970s. Our analysis suggests this is unlikely to be related to increased differences between potential and actual experience, sources of selection over time, or to particular data sources. Further analysis of the determinants of the returns to experience seems warranted to provide a coherent explanation for these trends.

\section{References}

Aghion, P. and P. Howitt. "Growth and Unemployment." Review of Economic Studies 61 (1994) 477-494.

Autor, David H., Lawrence F. Katz, and Melissa S. Kearney. "Trends in U.S. Wage Inequality: Revising the Revisionists." Review of Economics and Statistics 90 (2008) 300-323.

Ball, Laurence and Robert Moffitt. "Productivity Growth and the Phillips Curve." In The Roaring Nineties: Can Full Employment Be Sustained? Alan B. Krueger and Robert M. Solow, eds. New York: Russell Sage Foundation, 2001.

Blanchard, Olivier J. "Technological Change, Productivity Growth, and Unemployment." Mimeo., MIT (1998).

Blanchard, Olivier J. "The Economics of Unemployment: Shocks, Institutions, and Interactions." Lionel Robbins Lectures (2000). 
Blanchard, Olivier J. "A Review of Richard Layard, Stephen Nickell, and Richard Jackman's Unemployment: Macroeconomic Performance and the Labour Market." Journal of Economic Literature 45 (2007) 410-418.

Blanchard, Olivier J. and Lawrence H. Summers. "Hysteresis and the European Employment Problem." NBER Macroeconomics Annual 1 (1986) 15-78.

Blanchard, Oliver J. and Justin Wolfers. "The Role of Shocks and Institutions in the Rise of European Unemployment: the Aggregate Evidence." Economic Journal 110 (462) 1-33.

Blau, Francine D. "Trends in the Well-Being of American Women, 1970-1995." Journal of Economic Literature 36 (1998) 112-165.

Blinder, Alan S. and Yoram Weiss. "Human Capital and Labor Supply: A Synthesis." Journal of Political Economy 84 (1976) 449-472.

Bruno, Michael and Jeffrey Sachs. Economics of World Wide Stagflation. Cambridge, MA: Harvard University Press, 1985.

Heckman, James J. "A Life-Cycle Model of Earnings, Learning, and Consumption." Journal of Political Economy 84 Part 2: Essays in Labor Economics in Honor of H. Gregg Lewis (1976) S9-S44.

Heckman, James J., Lance Lochner and Petra Todd. "Earnings Functions, Rates of Return, and Treatment Effects: The Mincer Equation and Beyond." In E. Hanushek and F. Welch, eds., Handbook of the Economics of Education, Vol. 1, Chapter 7, Amsterdam: Elsevier Science, 2007.

Layard, Richard, Stephen Nickell, and Richard Jackman. Unemployment: Macroeconomic Performance and the Labour Market. Oxford: Oxford University Press, 1991 
Juhn, Chinhui, Kevin M. Murphy, Robert H. Topel. "Why has the Natural Rate of Unemployment Increased over Time?" Brookings Papers on Economic Activity (2:1991) 75-142.

Juhn, Chinhui, Kevin M. Murphy, Robert H. Topel. "Current Unemployment, Historically Contemplated." Brookings Papers on Economic Activity (1:2001) 79-116.

Katz, Lawrence F. and David H. Autor, "Changes in the Wage Structure and Earnings Inequality," Handbook of Labor Economics, Volume 3, edited by O. Ashenfelter and D. Card, 1999 Elsevier.

Katz, Lawrence F. and Kevin M. Murphy. "Changes in Relative Wages, 1963-1987: Supply and Demand Factors." Quarterly Journal of Economics 107 (1992) 35-78.

Lee, Chul-In. "On-the-Job Human Capital Investment and Intertemporal Substitution: New Evidence on Intertemporal Substitution Elasticity." Journal of Economic Dynamics \&J Control 32 (2008) 3350-3375.

Manning, Alan "Productivity Growth, Wage Setting, and the Equilibrium Rate of Unemployment." Centre for Economic Performance Discussion Paper no. 63 (1990).

Mortensen, Dale, and Christopher Pissarides "Technological Progress, Job Creation, and Job Destruction." Review of Economic Dynamics 1 (1998) 733-753.

Olivetti, Claudia. "Changes in Women's Hours of Market Work: The Role of Returns to Experience." Review of Economic Dynamics 9 (2006) 557-587.

Pierce, Brooks. "Compensation Inequality." Quarterly Journal of Economics 116 (2001) 1493-1525.

Rubinstein, Yona, and Yoram Weiss. "Post Schooling Wage Growth: Investment, Search and Learning." In E. Hanushek and F. Welch, eds., Handbook of the Economics of Education, Vol. 1, Chapter 1, Amsterdam: Elsevier Science, 2006. 
Ryder, Harl E., Frank P. Stafford, Paula E. Stephan. "Labor, Leisure and Training over the Life Cycle." International Economic Review 17 (1976) 651-674.

Shaw, Kathryn L. "Life-Cycle Labor Supply with Human Capital Accumulation." International Economic Review 30 (1989) 431-456.

Smith, James P., and Finis R. Welch. "Black Economic Progress After Myrdal." Journal of Economic Literature 27 (1989) 519-564.

Staiger, Douglas, James H. Stock, and Mark W. Watson. "Prices, Wages, and the U.S. NAIRU in the 1990s." In The Roaring Nineties: Can Full Employment Be Sustained? Alan B. Krueger and Robert M. Solow, eds. New York: Russell Sage Foundation, 2001.

Weinberg, Bruce A. "Experience and Technology Adoption." Mimeo., Ohio State University, 2005.

Welch, Finis. "The Employment of Black Men." Journal of Labor Economics 8 Part 2: Essays in Honor of Albert Rees (1990) S26-S74.

Willis, Robert J. and Sherwin Rosen. "Education and Self-Selection." Journal of Political Economy 87 Part 2: Education and Income Distribution (1979) S7-S36. 


\section{Appendix}

\section{A Theoretical Results}

Derivation of Equation (1) Imagine firms face a constant returns to scale production technology that uses efficiency units of labor $A(x, t) n$, as well as capital $k$ to produce output $y$ according to

$$
y=F(A(x, t) n, k) \text {, where } A(x, t) \equiv e^{g_{w} t+g_{x} x} .
$$

From the linear homogeneity of the production technology, the marginal products are homogeneous of degree zero, so that we can write

$$
F_{j}(A(x, t) n, k)=F_{j}\left(A(x, t) \frac{n}{k}, 1\right) \equiv f_{j}\left(A(x, t) \frac{n}{k}\right), \text { for } j=1,2 .
$$

Using this, the first order condition for optimal capital demand implies $A(x, t) \frac{n}{k}=f_{2}^{-1}\left(p_{k}\right)$, where $p_{k}$ is the price of capital. Substituting into the first order condition for optimal employment, we obtain $w(x, t)=A(x, t) f_{1}\left(f_{2}^{-1}\left(p_{k}\right)\right)$. Taking logs and defining $w(0,0) \equiv$ $f_{1}\left(f_{2}^{-1}\left(p_{k}\right)\right)$ yields the equation (1) stated in the main text.

Proof of Proposition 1 Consider a worker with experience $x$ at time $t$ who is just indifferent to working, so that $w(x, t)=w_{R}(x, t)$. Note that the time derivative of the market wage is given by

$$
\dot{w}=g_{w} w(x, t)+h(x, t) w_{x}(x, t)
$$

since $\dot{x}=h(x, t)$. Likewise, noting that $\dot{b}=g_{w} b(t)$, and $\dot{\lambda}=r \lambda(t)-h(x, t) w_{x}(x, t)$, the time derivative of the reservation wage is given by

$$
\dot{w}_{R}=g_{w} w_{R}(t)-\left(r-g_{w}\right) \lambda(t)+h(x, t) w_{x}(x, t) .
$$


It follows that, when the individual is just indifferent between working or not, the time derivative of the difference between the wage and the reservation wage is given by

$$
\left.\left(\dot{w}-\dot{w}_{R}\right)\right|_{w=w_{R}}=\left(r-g_{w}\right) \lambda(t) .
$$

Under the assumptions that $r-g_{w}>0$ and $w_{x}(x(\tau), \tau)>0$ for all $\tau$, the shadow value of experience in equation (12) has the property that

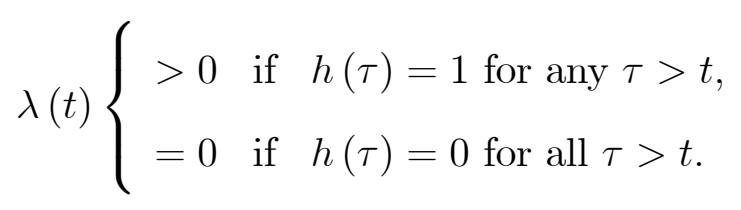

Given this, we can conclude that

$$
\left.\left(\dot{w}-\dot{w}_{R}\right)\right|_{w=w_{R}}\left\{\begin{array}{lll}
>0 & \text { if } & h(\tau)=1 \text { for any } \tau>t, \\
=0 & \text { if } & h(\tau)=0 \text { for all } \tau>t .
\end{array}\right.
$$

Equation (23) implies that, whenever a worker is indifferent between working or not at a point in time, two outcomes are possible: If he intends to work at any point in the future, he will start working now and will work for the rest of his life, since his offered market wage is rising above his reservation wage from below. On the other hand, if he never intends to work in the future, he will be indifferent between working and not working for the rest of his life. It follows that any wage offer slightly above the reservation wage will lead a worker to work for the rest of his life, and any offer slightly below his reservation wage will lead a worker to not work for the rest of his life.

\section{B Potential vs. Actual Experience in PSID Data}

A potential confound to the evidence of a flattening of the observed potential experience earnings profile among high school dropouts in Figures 2A and 4A is that the gap between 
potential and actual labor market experience widened for this group of workers over time as their employment rates fell. Figure 5 provides an upper bound on the size of this effect by assuming that employment is i.i.d. across workers, so that actual experience is well approximated by the employment rate times potential experience.

As mentioned in the main text, the latter is an upper bound since employment is unlikely to be i.i.d. across workers, especially among the full time full year workers that we focus on. In this appendix, we use data from the core sample of the Panel Study of Income Dynamics to explore this possibility further. The sample restrictions imposed mirror those used in the Census samples described in the main text. We focus on full time full year white male household heads aged 16 to 64 with 9 to 11 years of completed schooling.

Potential experience is constructed as age minus years of completed schooling minus six. ${ }^{25}$ Actual experience is constructed as follows. In the first year a respondent is observed, the actual experience calendar is intialized using data on the number of years worked since age 18. ${ }^{26}$ Actual experience is then updated in each consecutive survey by adding the fraction of weeks worked in the survey year to the cumulative value of actual experience in prior years.

Figure B1 presents the results of this exercise for PSID data pertaining to the years 1967 to $1996 .^{27}$ It plots measures of average actual experience against potential experience from the method described above. Years of data are pooled into three groups to obtain larger sample sizes. The results suggest that there has indeed been a divergence between potential and actual experience in the later years of the sample, consistent with the fact that employment rates have fallen among high school dropouts. However, the magnitudes

\footnotetext{
${ }^{25}$ Years of completed schooling are available only in intervals for the years 1969 to 1974 inclusive. For those years, years of schooling equal are set equal to the value reported in 1968, if it is observed and is consistent with the intervalled variable in subsequent surveys. Otherwise, we assign the midpoint value of the intervalled data.

${ }^{26}$ Data on the number of years worked since age 18 is unavailable prior to 1974 . Consequently, respondents who worked only prior to 1974 were excluded. For respondents who worked before and after 1974, the number of years worked is backcasted using information in the pre-1974 surveys on whether the respondent worked.

${ }^{27}$ The switch to a biennial survey in 1997 complicates the construction of the actual experience variable, since it does not contain data on employment in the year prior to the survey year.
} 
of these effects are somewhat smaller than those assumed in Figure 5. There it was assumed that the ratio of actual to potential experience was equal to 0.9 in 1970 , and 0.75 in 2000 , the respective trend employment rates in those two periods. The results in Figure B1 suggest that the ratio dropped from 0.9 to 0.8 , suggesting that the exercise underlying Figure 5 is indeed an upper bound. 
Figure 1. Nonemployment Rates for White Males: Aggregate and by Education

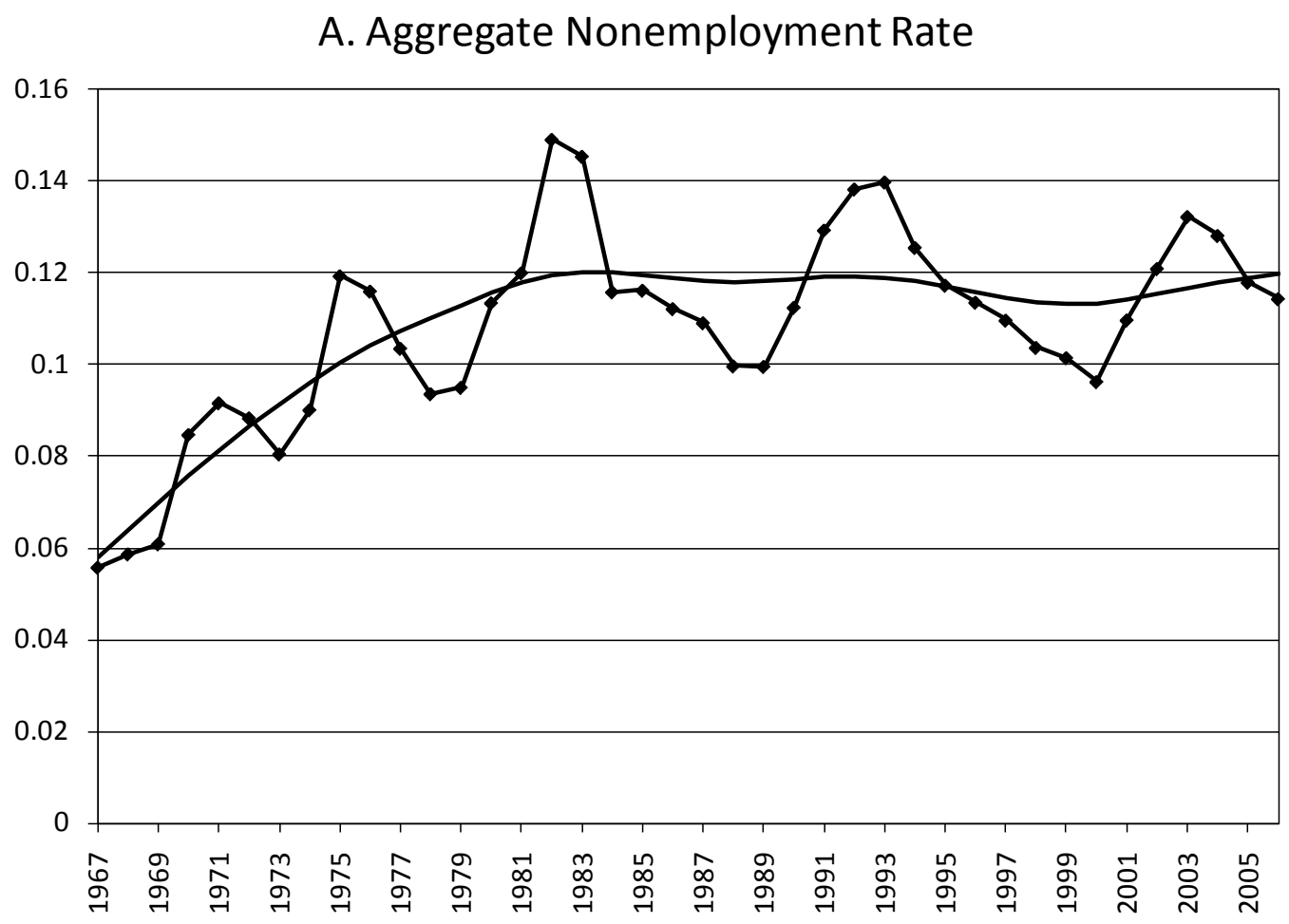

B. Nonemployment Rates by Education

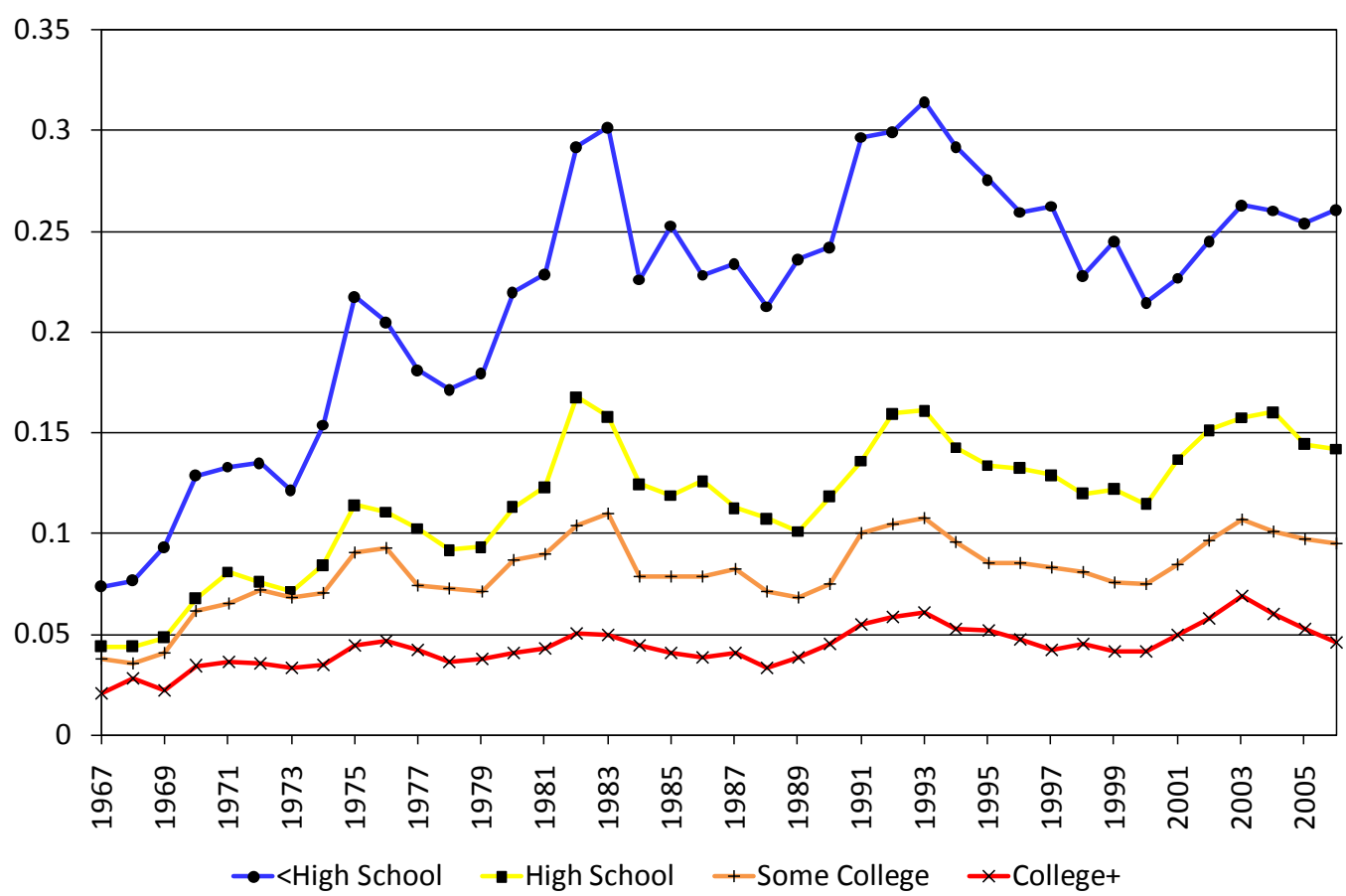

Notes: Data are taken from March Current Population Survey microdata for white males aged 16 to 64 with fewer than 30 years of potential experience, who report that they are neither students nor self employed. Nonemployment rates are computed as the fraction of year spent out of work. Weeks worked prior to 1976 are intervalled. Nonemployment rates prior to 1976 are computed by applying within-interval means from post-1976 data to pre-1976 data. Bold black lines are HP trends with an annual smoothing parameter of 100 . 
Figure 2. Experience-Earnings Profiles, by Education and Census Year
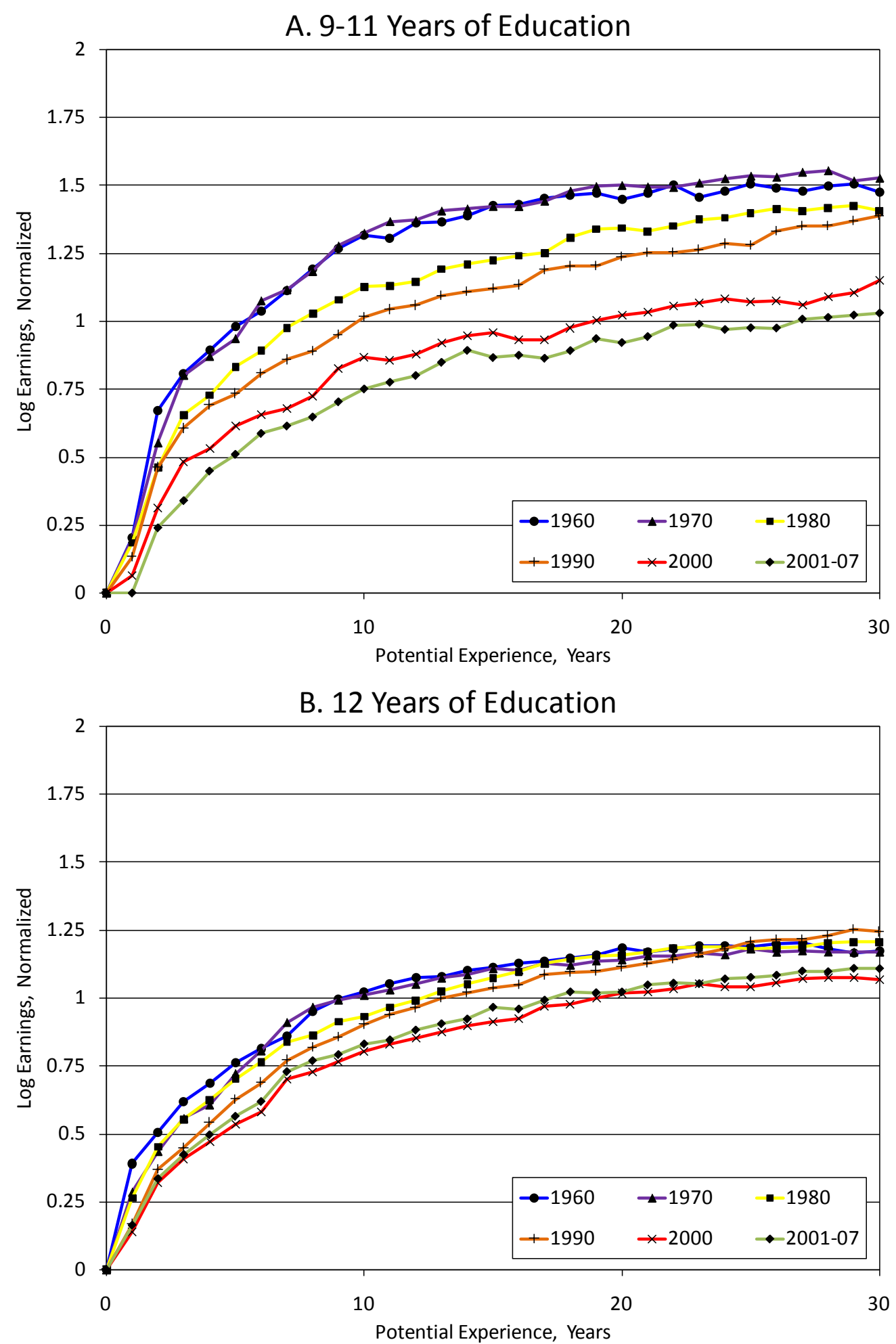
Figure 2. Experience-Earnings Profiles, by Education and Census Year (continued)
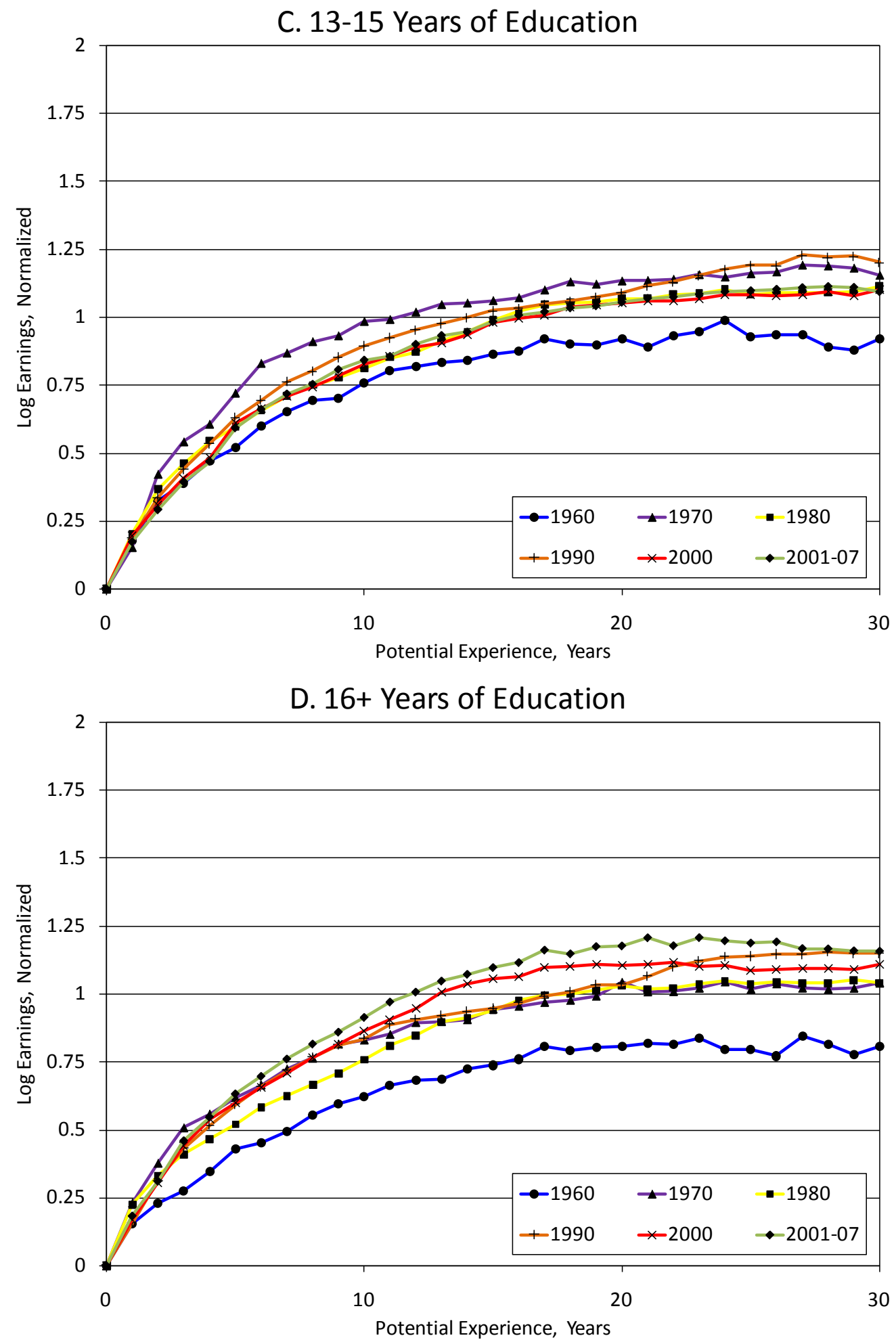

Notes: Profiles are based on data for full-time, full-year white males aged 16 to 64 from the 1960 to 2000 decennial Censuses, and pooled 2001 to 2007 American Community Survey samples. Mean log earnings are normalized by the mean log earnings of workers entering the labor market. 
Figure 3. Capitalized Value of Earnings, Normalized to 1970, 9-11 Years of Education, by Census Year and Discount Rate

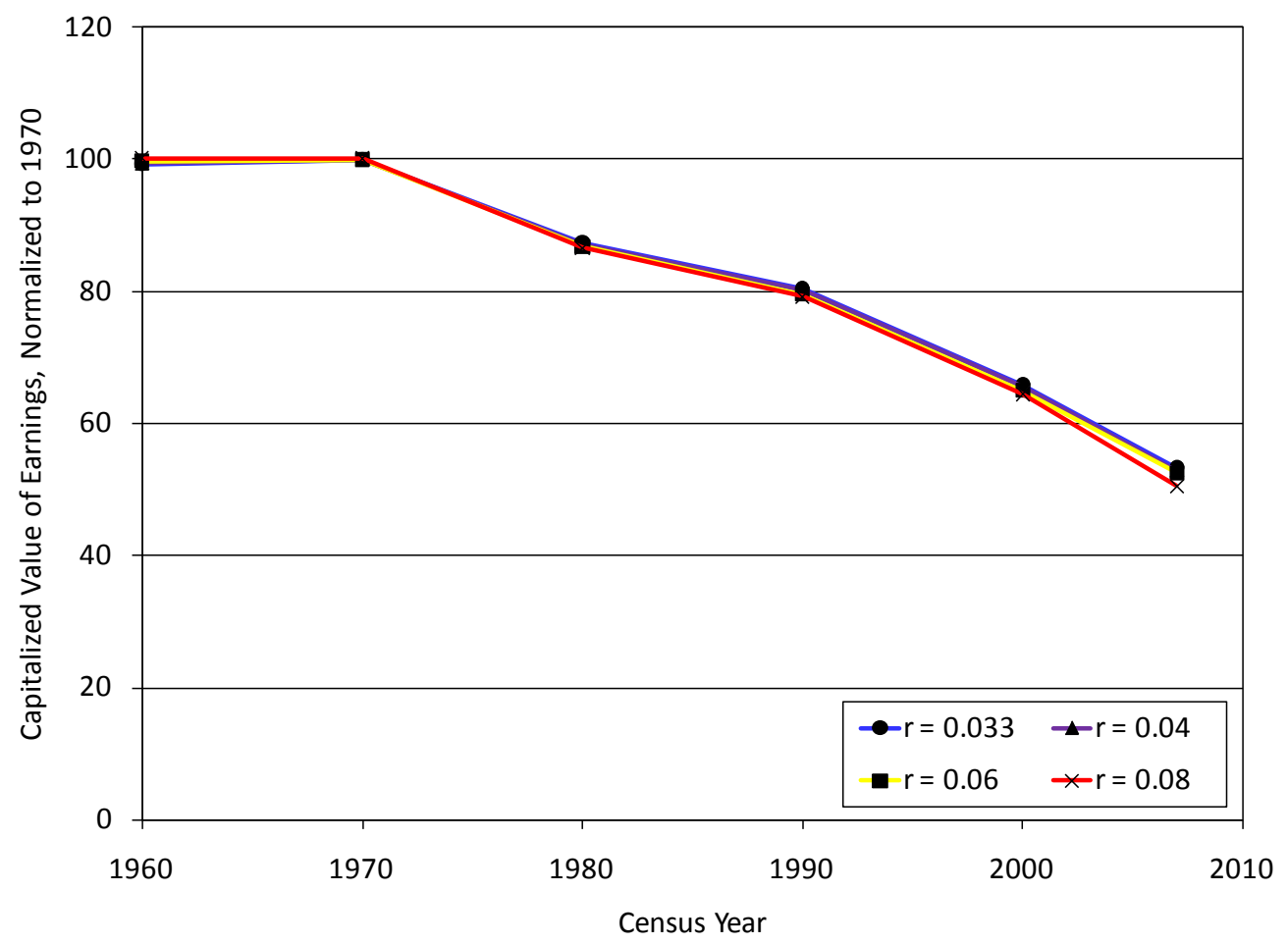

Notes: Authors' calculations of the capitalized value of earnings over a thirty year horizon, discounted at rate $r$, and normalized to equal 100 in 1970. Data used for the calculation are the experience profiles for 9-11 years of education underlying Figure 2A. 
Figure 4. Earnings Profiles by Cohort and Education

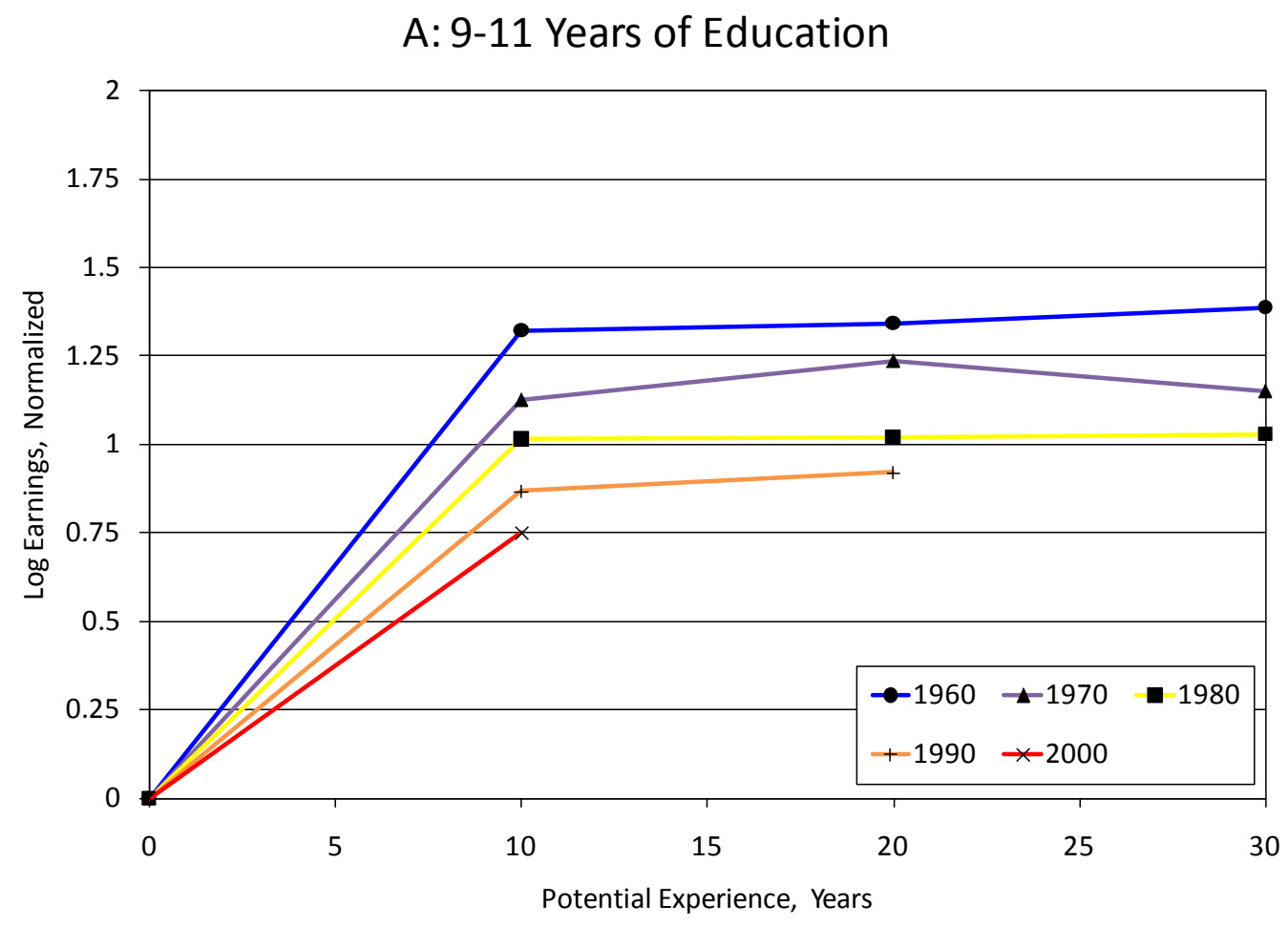

\section{B: 12 Years of Education}

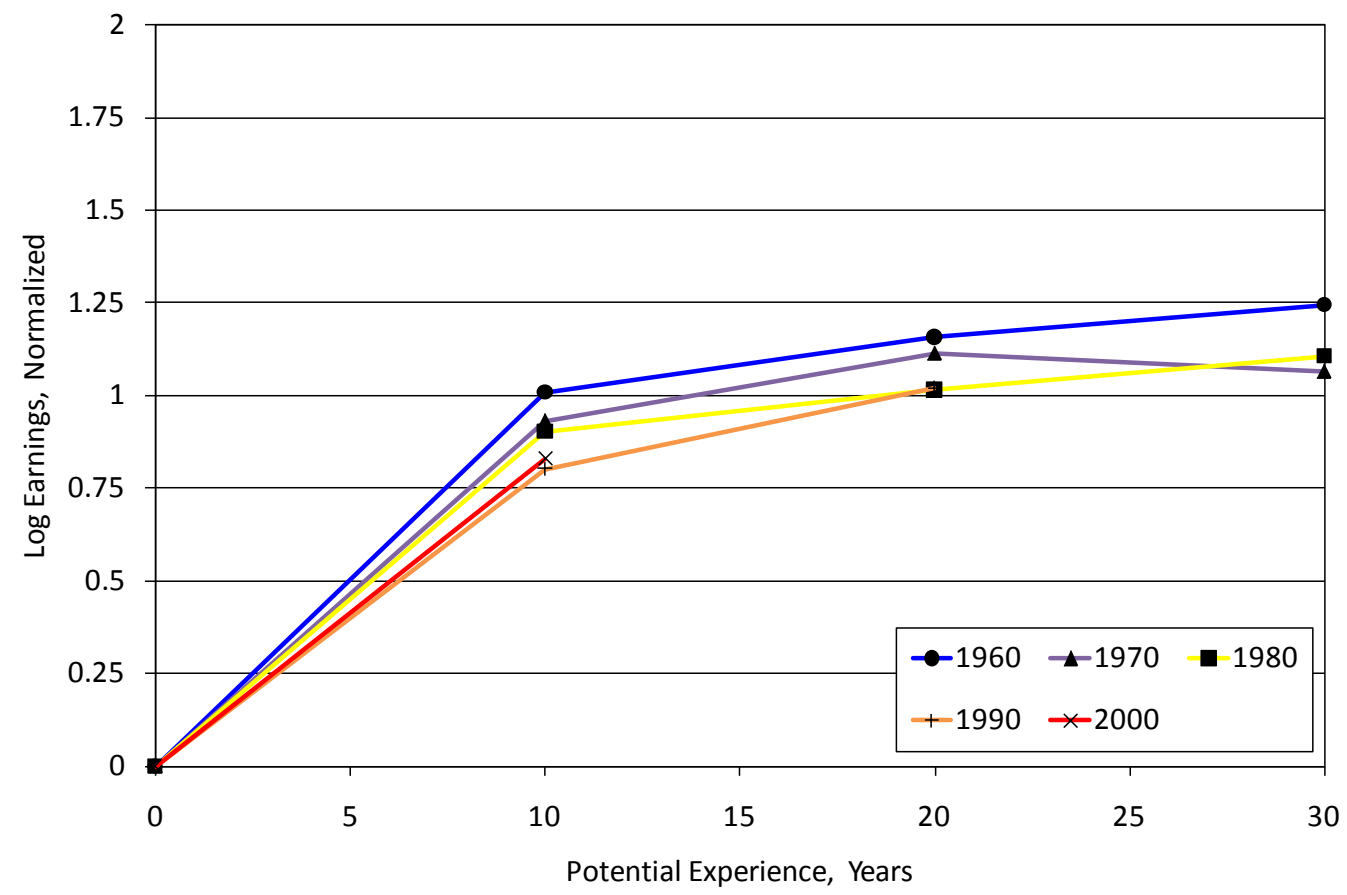


Figure 4. Earnings Profiles by Cohort and Education (continued)

C: $13-15$ Years of Education

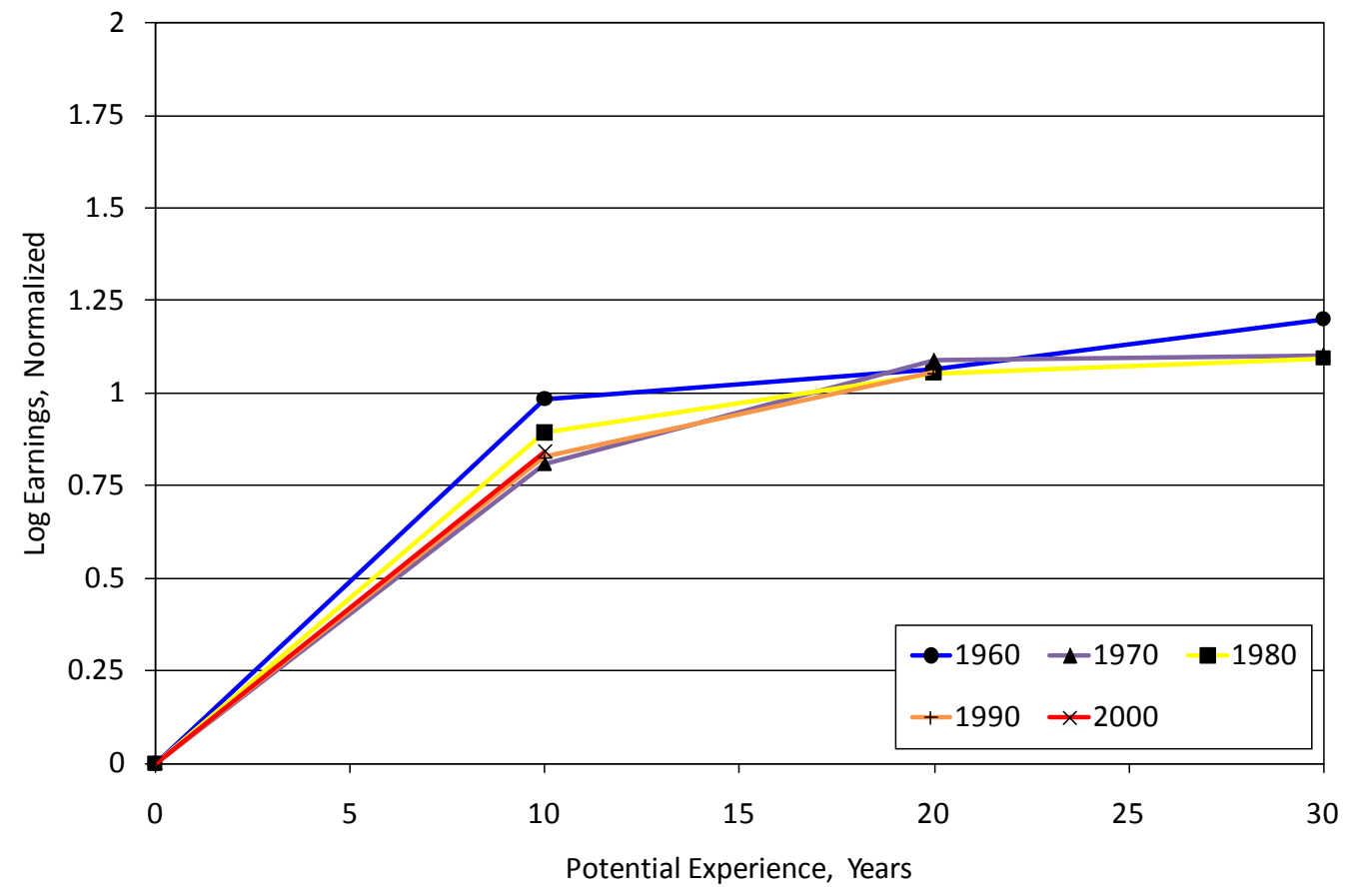

D: $16+$ Years of Education

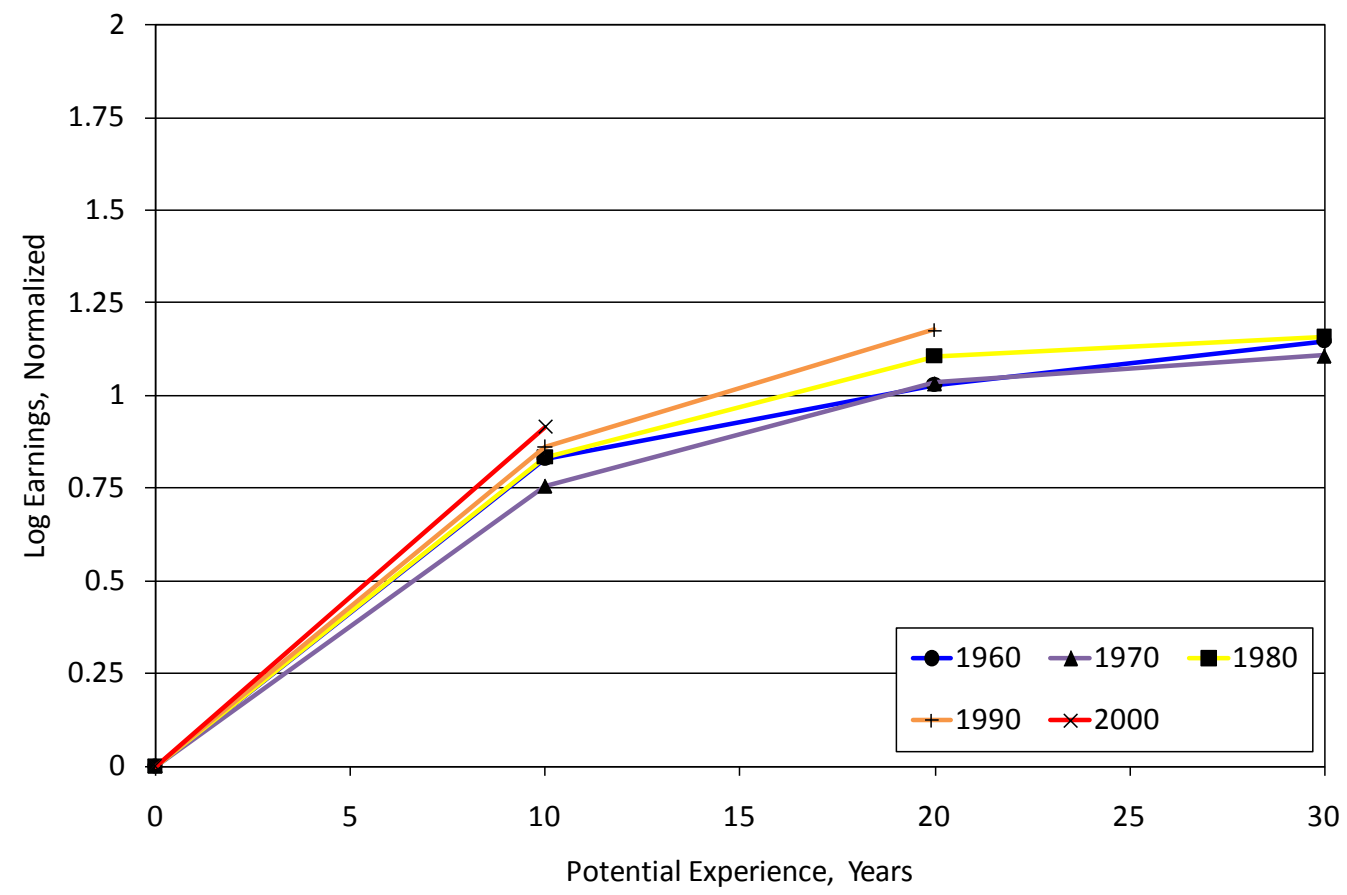

Notes: Profiles are based on same data as those underlying Figure 2. Mean log earnings are normalized by the mean log earnings of workers entering the labor market. Data points for 2010 are imputed under the assumption that the experience-earnings profile from pooled 2001 to 2007 ACS data is time invariant. 
Figure 5. Potential vs. Actual Experience and Changes in Experience-Earnings Profiles among High School Dropouts

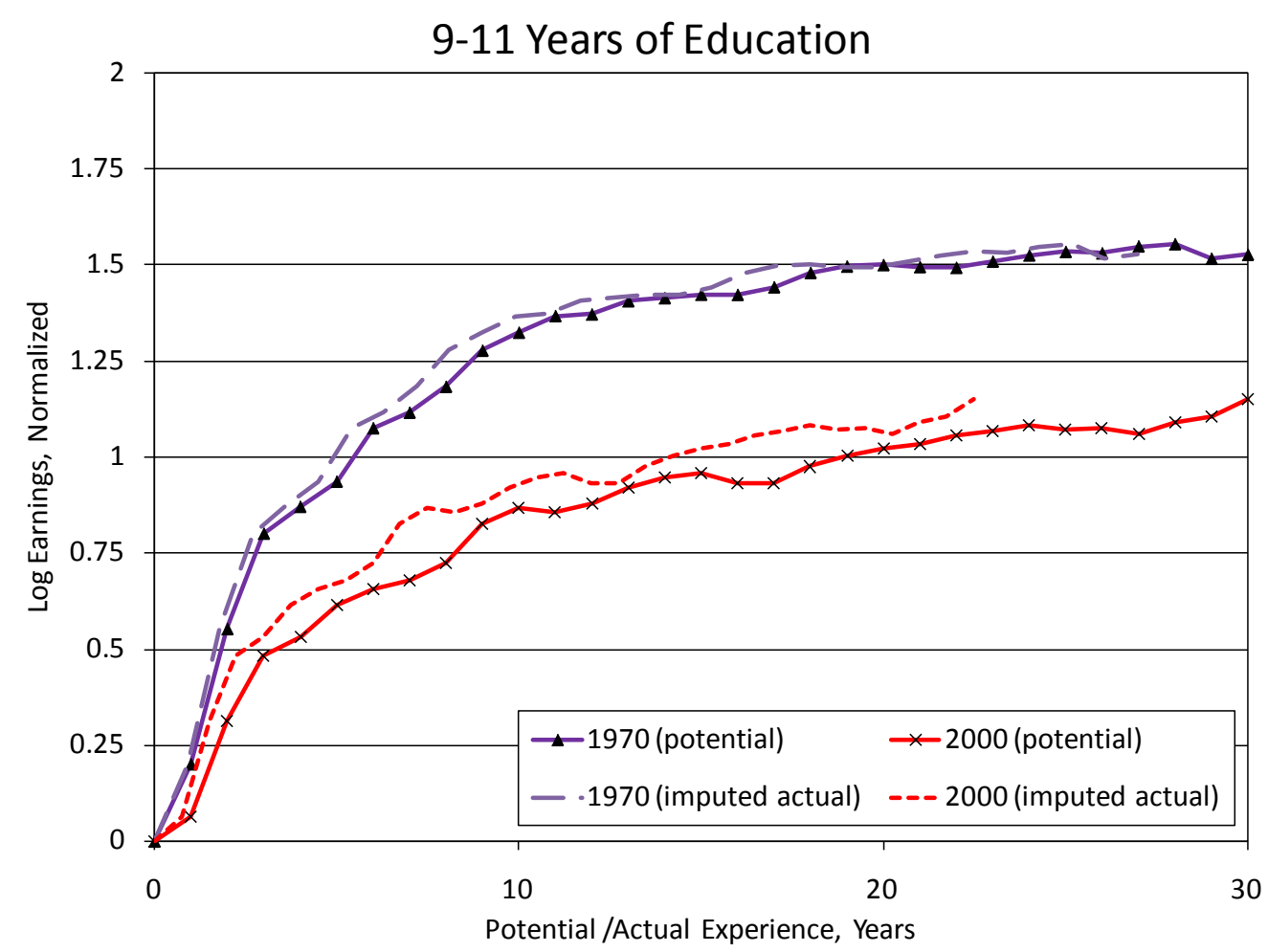

Notes. Non-dashed lines are cross-sectional potential experience-earnings profiles among fulltime, full-year white males aged 16 to 64 from the 1970 and 2000 decennial Censuses replicated from Figure 3A. Dashed lines represent actual experience-earnings profiles that would be observed under steady state employment rates of 90 percent in 1970 and 75 percent in 2000, assuming that employment is i.i.d. across workers. 
Figure 6. 25/5 Experience Premium by Education: Census vs. Current Population Survey
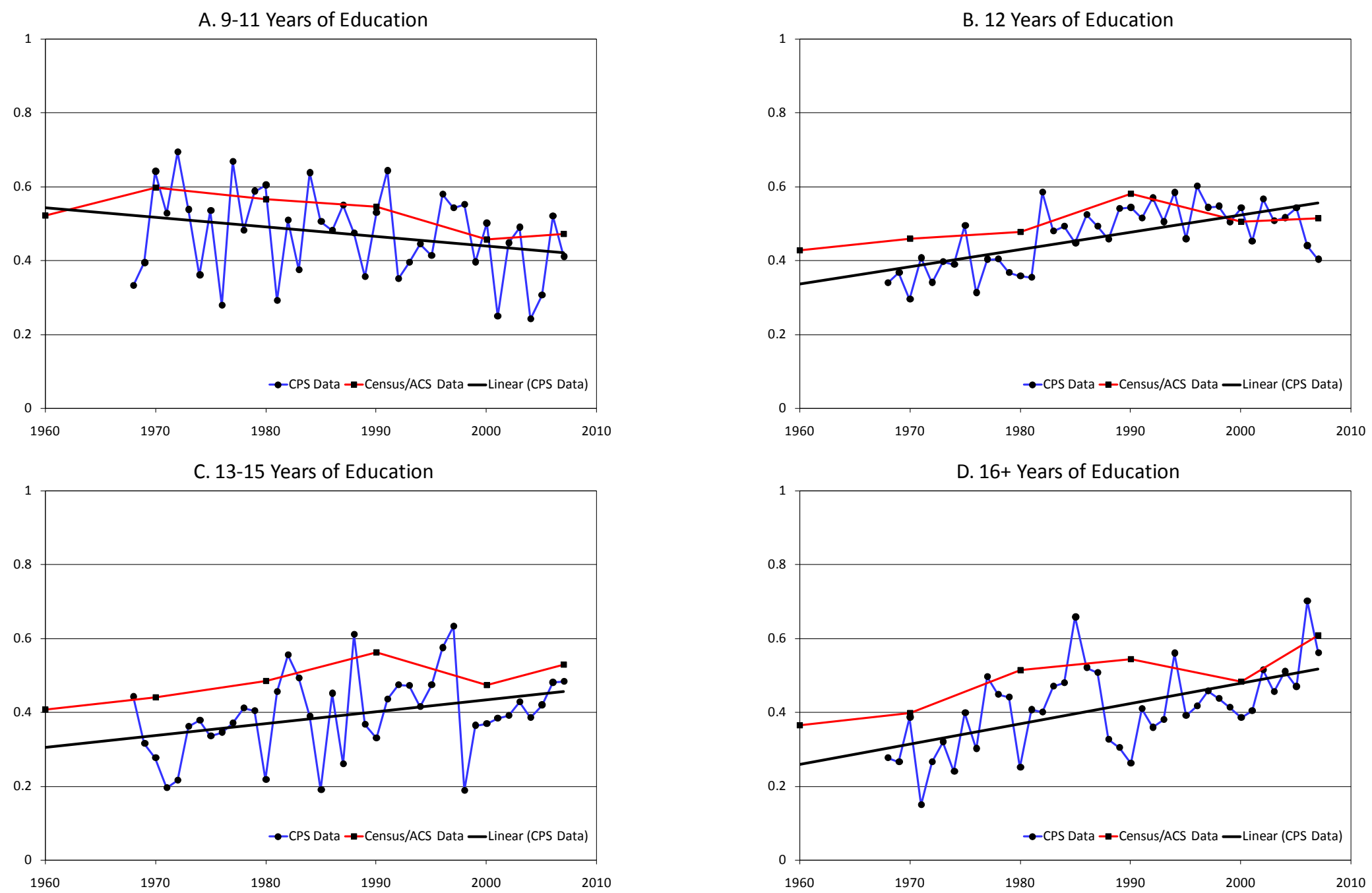

Notes: The 25/5 experience premium is defined as the difference in mean log earnings among workers with 25 vs. 5 years of experience among full-time, full-year white males aged 16 to 64. Data are taken from the decennial Censuses from 1960 to 2000 , pooled 2001 to 2007 American Community Surveys, and March Current Population Survey microdata. The black bold lines plot linear time trends of CPS data. 
Figure 7. Trend Hourly Wage Growth by Education

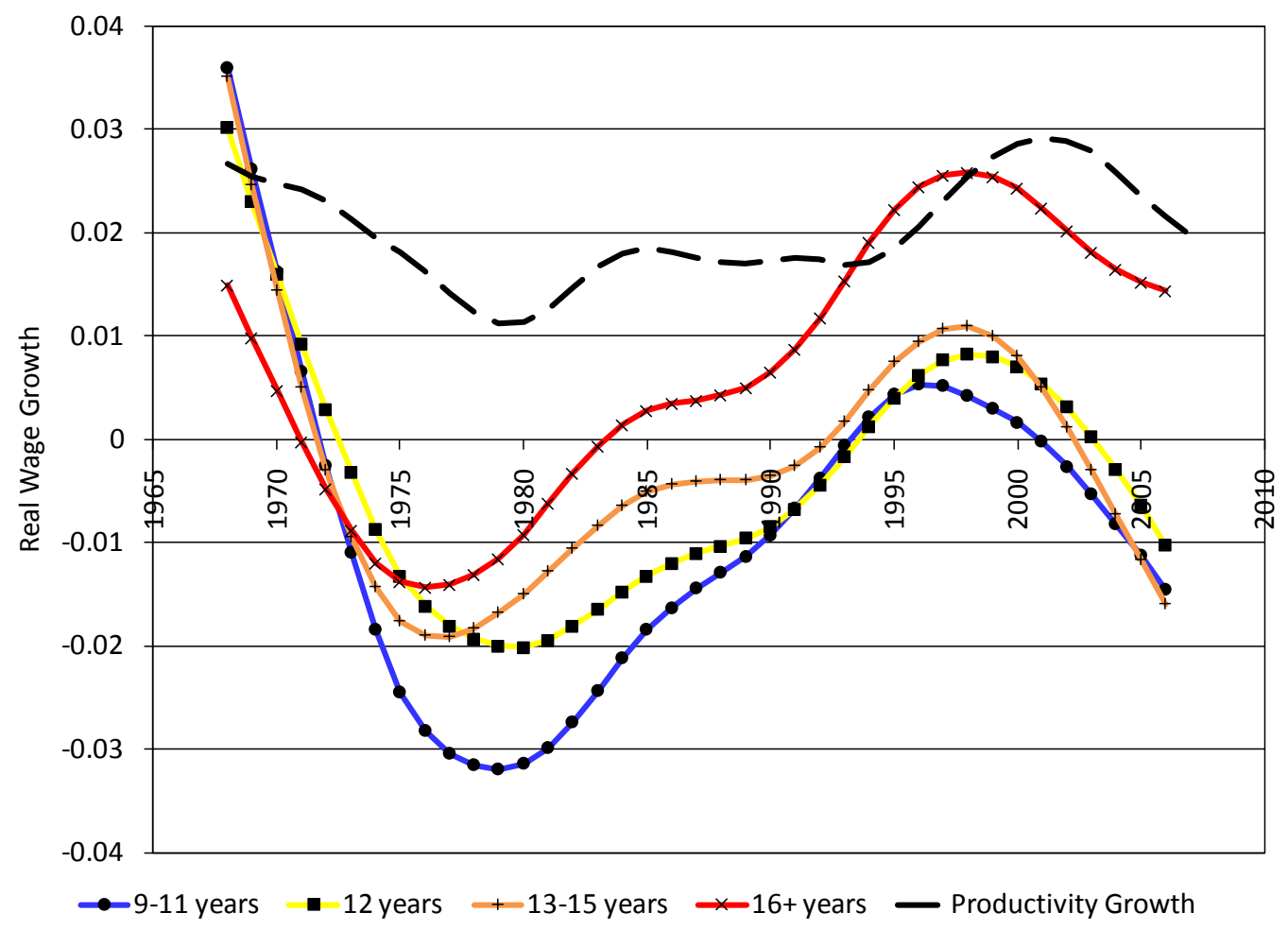

Notes: Authors' calculations based on March Current Population Survey microdata from 1968 to 2006. The series report HP filtered real wage growth by education group. Data are for white males aged 16 to 64 with fewer than 30 years of labor market experience. Hourly wages are computed by dividing weekly wages by weekly hours. Productivity growth is computed from the BLS output per hour series for the business sector and then smoothed using the HP filter. 
Figure 8. Simulated Response of Nonemployment Rate to an Unanticipated, Permanent Decline in Aggregate Wage Growth

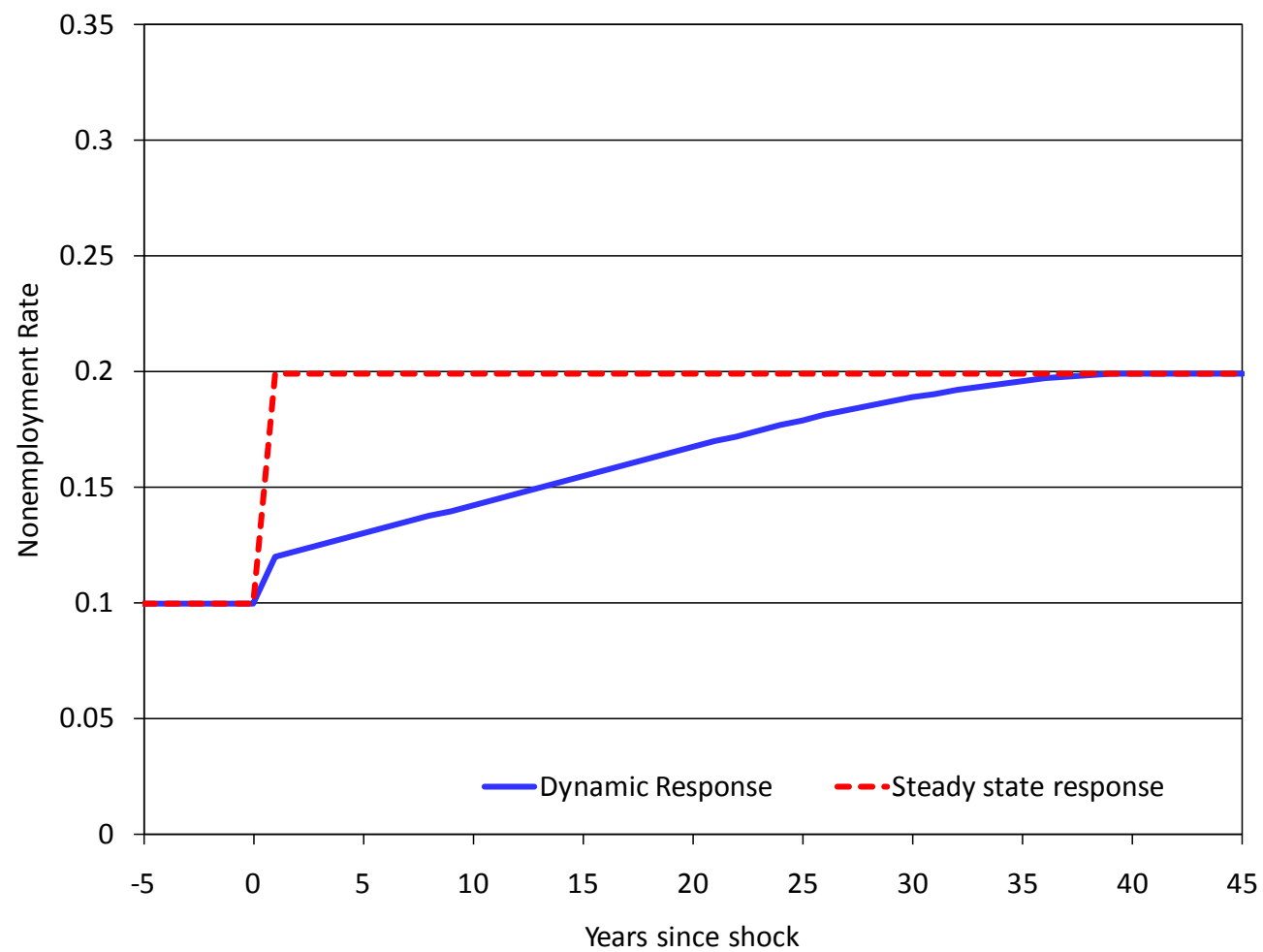

Notes: Authors' calculations based on general model of Section IV. Figure plots the response to a permanent unanticipated decline in $g_{w}$ from 3 percent to -3 percent. The discount rate $r=0.04$, and the experience-earnings profile is fixed at its 1980 level in Figure 2A. 
Figure 9. Implied Response of Nonemployment among High School Dropouts to Observed Changes in Experience-Earnings Profile and Aggregate Wage Growth

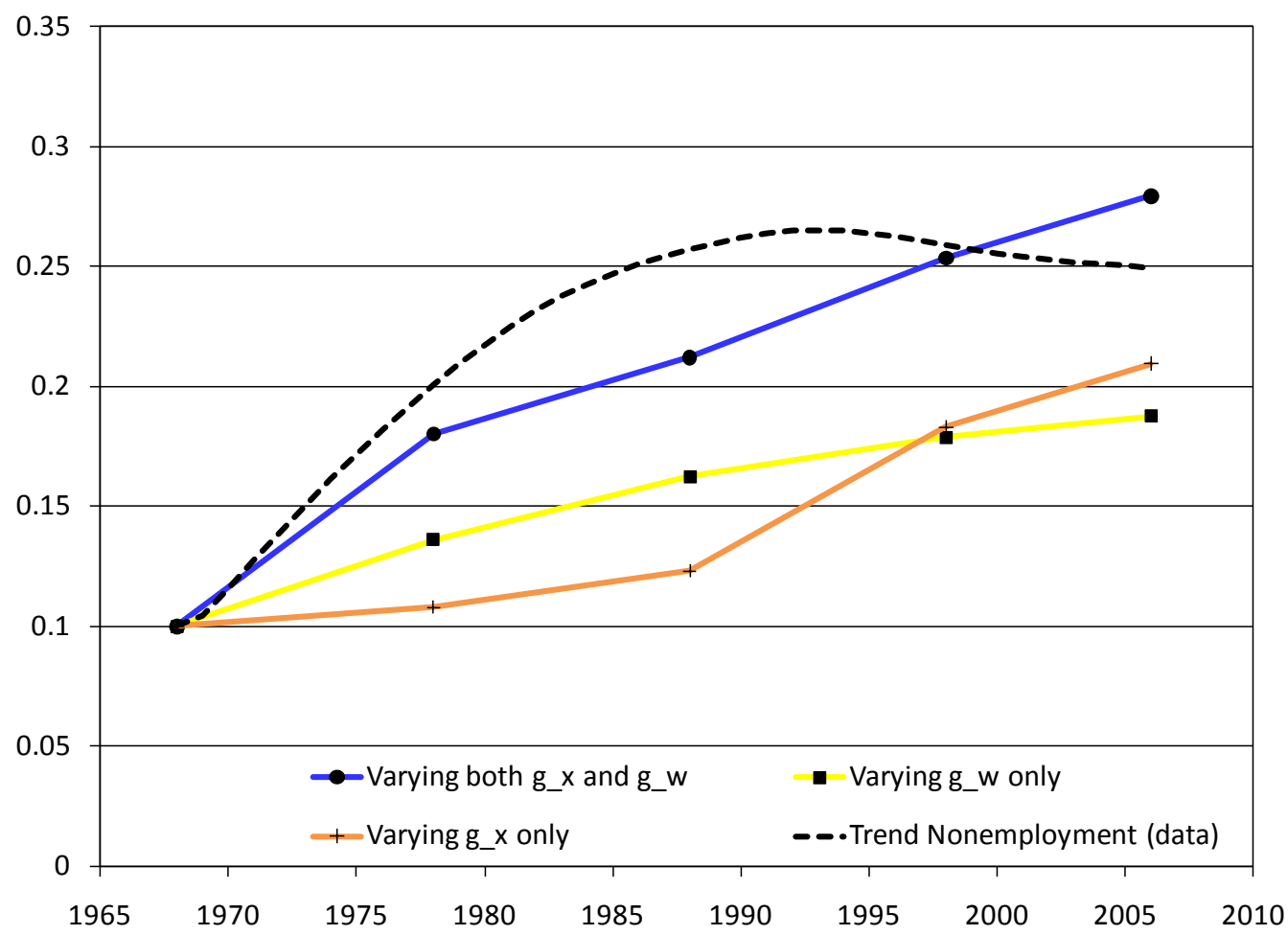

Notes: Authors' calculations based on general model of Section IV. Observed changes in the experience-earnings profile (Figure 2A) and aggregate wage growth (Figure 7) are fed through the model as unanticipated shocks. The discount rate $r=0.04$. The simulation that varies $g_{w}$ only (yellow line) holds the experience-earnings profile fixed at its 1980 level in Figure 2A. The simulation that varies $g_{x}$ only (orange line) holds aggregate wage growth fixed the temporal mean of the series for high school dropouts in Figure 7 (approximately zero). 
Figure 10. Age Structure of Rise in Nonemployment Implied by the Model

\section{A. Model}

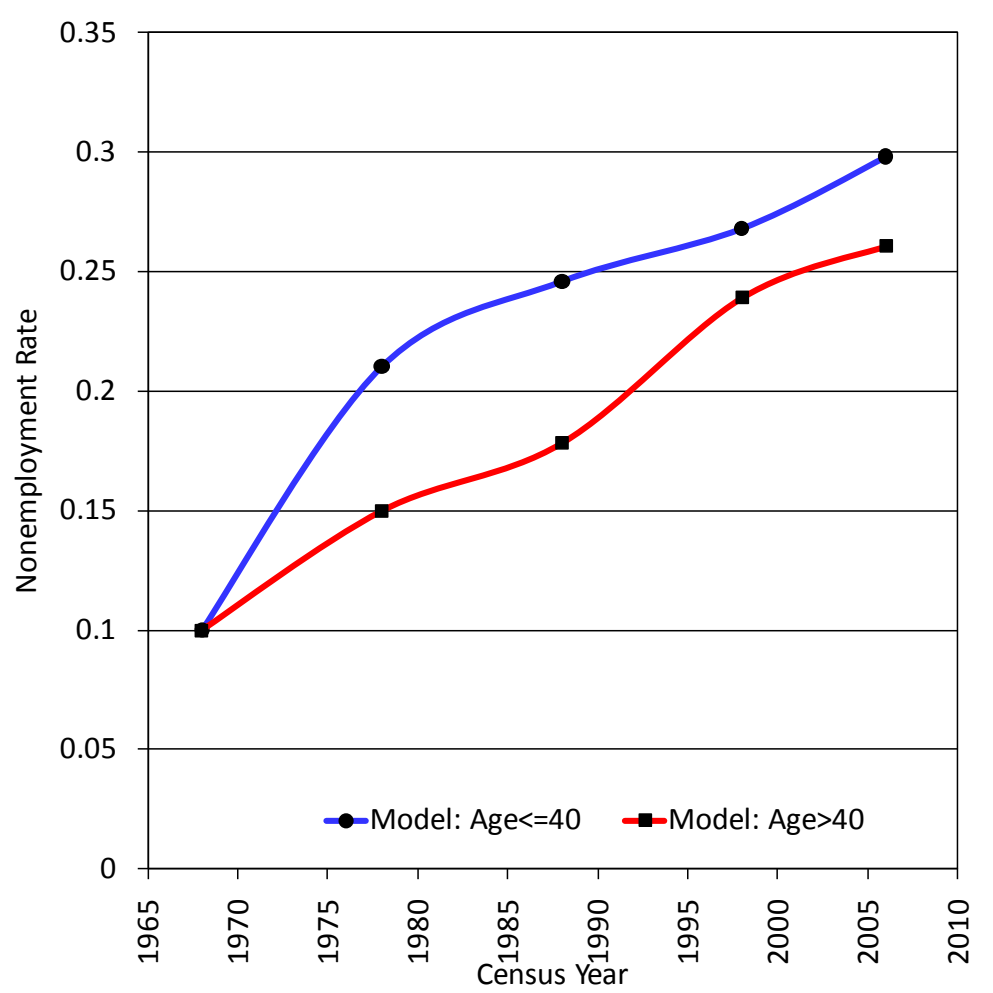

B. Data



Notes: Model calculations are based on the general model of Section IV. Observed changes in the experience-earnings profile and aggregate wage growth are fed through the model as unanticipated shocks. The discount rate $r=0.04$. Age 40 is interpreted as 20 years of working life in the model. Data are taken from March Current Population Survey microdata for white males aged 16 to 64 with fewer than 30 years of potential experience, who report that they are neither students nor self employed. Nonemployment rates are computed as the fraction of year spent out of work. Plotted lines are HP trends. 
Figure 11. Implied Response of Nonemployment by Education to Observed Changes in Experience-Earnings Profile and Aggregate Wage Growth
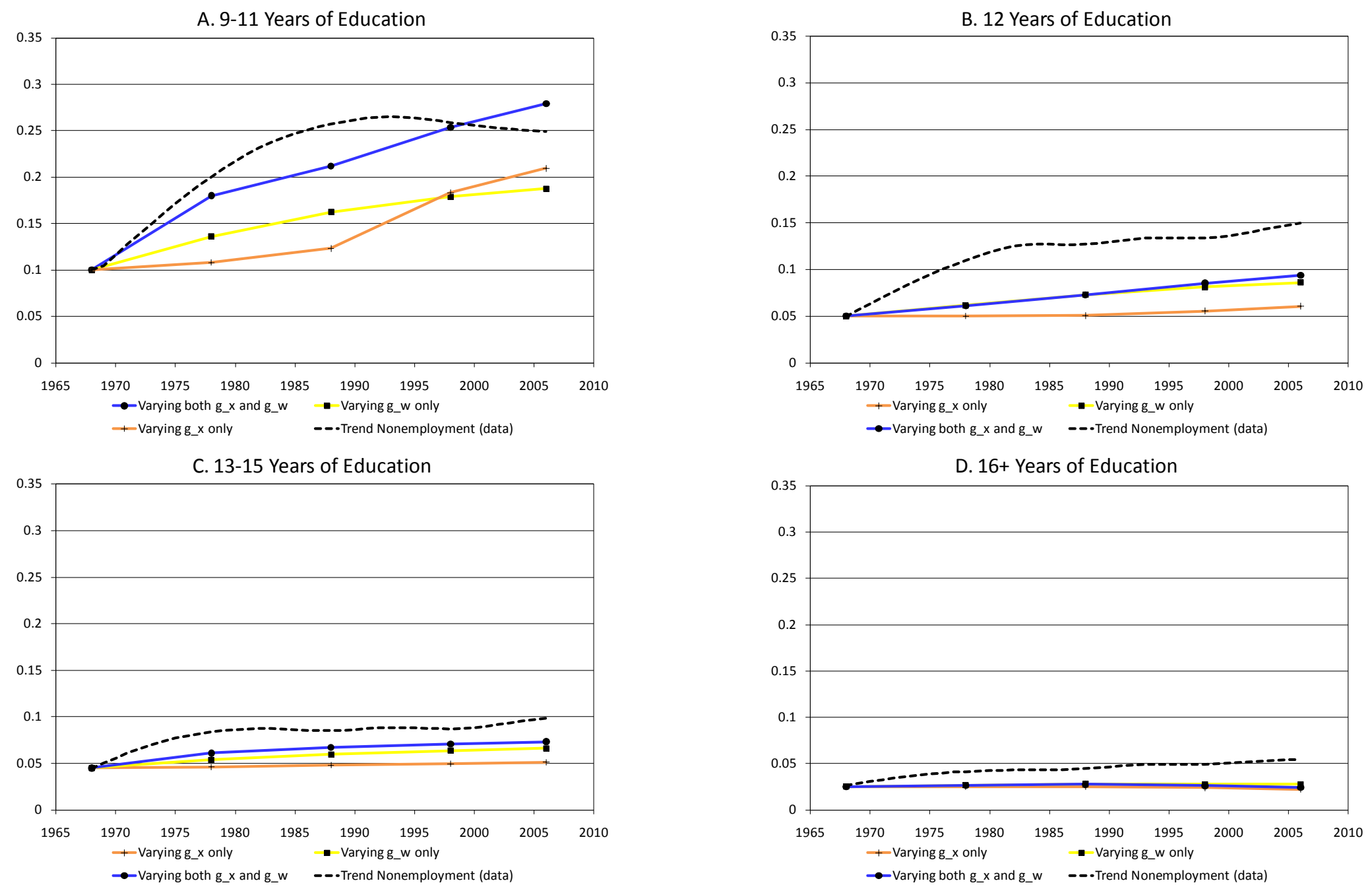

Notes: Authors' calculations based on general model of Section IV. Observed changes in the experience-earnings profile and aggregate wage growth are fed through the model as unanticipated shocks. The discount rate $r=0.04$. When the experience-earnings profile is fixed, it is held at its 1980 level. When aggregate wage growth is fixed, it is held at zero. 
Figure B1. Actual vs. Potential Experience among High School Dropouts in the Panel Study of Income Dynamics



Notes: Measures of average actual experience against potential experience for pooled years from the Panel Study of Income Dynamics. Non-dashed straight lines represent least squares regressions with the intercept constrained to equal zero. For details on the construction of the measures of actual and potential experience, see Appendix B. 